\title{
Wear Resistivity of Al7075/6wt.\%Sic Composite by using Grey-Fuzzy Optimization Technique
}

\author{
ABHIJIT BHOWMIK ( $\square$ abhijitbhowmik90@gmail.com ) \\ National Institute of Technology Agartala https://orcid.org/0000-0001-9409-0972 \\ Ajay Biswas \\ National Institute of Technology Agartala
}

\section{Research Article}

Keywords: Aluminium, SiC, Wear, Grey relational analysis, Fuzzy interface system.

Posted Date: April 28th, 2021

DOI: https://doi.org/10.21203/rs.3.rs-393129/v1

License: (9) This work is licensed under a Creative Commons Attribution 4.0 International License.

Read Full License 


\title{
Wear Resistivity of Al7075/6wt.\%Sic Composite by using Grey- Fuzzy Optimization Technique
}

\author{
Abhijit Bhowmik $^{1 *}$, Ajay Biswas ${ }^{2}$ \\ * Corresponding Author \\ Email: abhijitbhowmik90@gmail.com
}

ORCID ID: Abhijit Bhowmik https://orcid.org/0000-0001-9409-0972

${ }^{1}$ Research Scholar, Department of Mechanical Engineering

National Institute of Technology Agartala, India 799046

${ }^{2}$ Assistant Professor, Department of Mechanical Engineering

National Institute of Technology Agartala, India 799046

\begin{abstract}
Application of $\mathrm{SiC}$ particulate reinforcement impact greatly for making aluminium matrix composite because of its superb heat conductivity, oxidation stability and highly resistance to mechanical erosion. Present work based on dry sliding wear analysis of Al7075/6wt.\%SiC composite fabricated by liquid state stir casting method. To acquire a productive wear rate, three major process parameters viz. load, sliding speed and covering sliding distance were compared four different levels. ANOVA analysis showed that the probability rate of load is less than 0.05 that revealed their significant factor. From the study, the highest GRG and GFG values are found 0.914 and 0.854 respectively for the optimal operating parameters of 10 Newton load, 2 metre/second sliding speed and 500 metre sliding distance. Finally, it is revealed that the grey-fuzzy technique effectively authenticate the decision making of wear performance characteristics rather than a plain grey relational grade.
\end{abstract}

Keywords: Aluminium; SiC; Wear; Grey relational analysis; Fuzzy interface system.

\section{$\underline{\text { Abbreviations }}$}

$\begin{array}{ll}\text { MMC } & \text { Metal Matrix Composite } \\ \text { AMC } & \text { Aluminium Matrix Composite } \\ \text { SEM } & \text { Scanning Electron Microscope } \\ \text { EDX } & \text { Energy Dispersion X-ray spectroscopy } \\ \text { DOE } & \text { Design of Experiment } \\ \text { COF } & \text { Coefficient of Friction } \\ \text { MML } & \text { Mechanically Mixed Layer } \\ \text { GRA } & \text { Grey Relational Analysis } \\ \text { GRC } & \text { Grey Relational Coefficient } \\ \text { GRG } & \text { Grey Relational Grade } \\ \text { GFG } & \text { Grey Fuzzy Grade } \\ \text { FIS } & \text { Fuzzy Interface System } \\ \text { ANOVA } & \text { Analysis of Variance }\end{array}$




\section{Introduction}

Wear resistance capacity is a most significant aspect to be properly considered for making design elements that secure superb performance for various tribological applications [1]. MMC reinforced with particles reinforcements carried out superb strength, better wear performance, high hardness and impact strength that enhanced its application automobile and aircraft industry [2]. MMC obtained the ability to survive heavy tensile and compressive stresses during the transfer and dispersion of the concentrated load from unreinforced matrix to reinforced composite [3]. As compared to steel, aluminium is a good choice for its low density, high corrosion capacity and better mechanical properties. Aluminium is eminently used as a transporting medium for its light weight and low cost [4-6]. Mechanical strength of aluminium alloy enhanced with addition of some hard particulates reinforcement such as $\mathrm{SiC}$, $\mathrm{TiB}_{2}, \mathrm{~B}_{4} \mathrm{C}, \mathrm{Al}_{2} \mathrm{O}_{3}, \mathrm{TiC}, \mathrm{ZrB}_{2}$, fly ash etc. [7-9]. Ceramic particulates filled aluminium metal matrix composites reveals greater wear resistance capacity compared to base alloys [10]. Reinforcement gives preferred strength to composite in a superior direction. Reinforcement distributed in matrix according to different weight percentage in the formation of whisker or particles [11]. Non-homogeneous distribution of reinforcement particulates enhances the agglomeration behaviour and porosity that decreases the hardness strength of composite material [12]. Stir casting method is usually used fabrication method because of its low cost, easy to operate and flexibility. Stir casting generally used for melt aluminium, copper etc. Stir casting process preparing composite by mixing of matrix and reinforcement at a proper speed [13-15]. Stir casting is a satisfactory fabrication method for making composites up to $30 \mathrm{wt} . \%$ of reinforcement particles that reduce porosity and uniform distribution of reinforcement. A vital drawback of stir casting is the segregation of filler particles due to settling of filler particulates during melting [16]. Spheroidal grains generated with enhancing stirring time. At preliminary stage of stirring, few coarse dendrites are observed in microstructure [17]. Reinforcement weight percentage, type and size exhibit the minor changes on wear rate of metal matrix composites [18]. Reinforcement particle size plays a vital role in developing properties of composite, generally when particulates are microscale to nanoscale sizes [19]. Prasad et al. [20] investigated the mechanical and wear behaviour of $\mathrm{SiC} / \mathrm{TiB}_{2}$ particle reinforced Al6061 matrix composite fabricated by stir casting. it's noticed that $\mathrm{TiB}_{2}$ reinforced composite acquire more hardness and wear resistance as compared to $\mathrm{SiC}$ reinforced composite. Akbari et al. [21] established the nature of nano and micro grain size $\mathrm{TiB}_{2}$ particles reinforced aluminium matrix composites and observed that $\mathrm{TiB}_{2}$ particles significantly dispersed throughout the molten aluminium matrix. It is also concluded that UTS significantly reduced with enhancing the temperature of casting done and nano particle $\mathrm{TiB}_{2}$ reinforced composite have better ductility in nature as compared as micro particle. Bhowmik et al. [22] investigate mechanical properties and fracture behaviour of $\mathrm{SiC} / \mathrm{TiB}_{2}$ micro-sized powder reinforced aluminium matrix composite fabricated by stir casting and shown that $\mathrm{TiB}_{2}$ reinforced composite has additional strength related to $\mathrm{SiC}$ reinforced composite. Poria et al. [23] discussed the wear performance of $\mathrm{TiB}_{2}$ reinforced $\mathrm{Al}_{-} \mathrm{TiB}_{2}$ aluminium matrix composite and revealed that wear reduced with incorporation of $\mathrm{TiB}_{2}$ powder. Meti et al. [24] analyse tensile strength and fractography of $\mathrm{TiB}_{2}$ dispersed AA7075/TiB 2 composite fabricated by ultrasonic assisted stir casting. Result observed that 
$\mathrm{TiB}_{2}$ particles homogeneously distributed all over the matrix and ductility notably deuterated with enhancing $\mathrm{TiB}_{2}$ content. Raju et al. [25] reported the tribological performance of $\mathrm{Al} / \mathrm{CSA}$ composite by applying grey-fuzzy technique and noticed that wear rate reduced from 5.556 to 1.936 as per grey fuzzy grade. Chamarthi and Nagadolla [26] reported the machining performance of AL6082/SiC/Gr composite by applying grey-fuzzy approach and revealed that GFG notified best factor combination instead simple grey relational grade.

Based on earlier research work, it is observed that very few numbers of experimental work obtained about multi-objective optimization of wear behaviour on $\mathrm{SiC}$ reinforced aluminium matrix composite and a huge scope remaining to work in this field because $\mathrm{SiC}$ particle reinforced Al7075 matrix composites having a good range of applications in erosive and excessive temperature zone due to the mixture of superb thermal conductivity and low wear rate. The present research work is to evaluate the effect on SiC reinforced Al7075/6wt.\%SiC composite fabricated by a stir casting technique and analyses its dry sliding wear performance with the variation of three different factors and their four different levels by applying grey-fuzzy optimization technique.

\section{Experimentation}

\subsection{Materials}

A certain amount (900 gm) of Al7075 has chosen for matrix material and 6wt.\% SiC selected for ceramic agents with an average grain size of 20 micron. Chemical compound of aluminium alloy 7075 are Cr:-0.21\%, Fe:-0.22\%, Si:-0.04\%, Mg:-2.58\%, Mn-:0.03\%, Cu:1.65\%, Zn:-5.75\%, Ti:-0.03\% and Al-Remaining. Physical properties of SiC particles are: Density-3.21 g/ $\mathrm{cm}^{3}$, Melting point-2730 ${ }^{\circ} \mathrm{C}$, Purity-99\%, Formation-powder, Size-20 micron. Micrograph and EDX elemental mapping of SiC ceramic particles depicts in Fig. 1. Stir casting liquid state fabrication technique used for the present experiment to prepare aluminium matrix composites with the assist of mechanical stirrer which mixes homogeneously both matrix material and reinforcement particle. The schematic representation of the stir casting fabrication setup is shown in Fig.2. A graphite crucible is used for melting the aluminium ingot for composite preparation. After reaching $750^{\circ} \mathrm{C}$ pouring temperature, the actual weight percentage of titanium diboride poured within the molten matrix material and began stirring for 10 minutes. Mould and $\mathrm{SiC}$ reinforcement particles are preheated at $400^{\circ} \mathrm{C}$ and $450^{\circ} \mathrm{C}$ temperature respectively in a muffle furnace for reducing porosity, oxide formation, and material shrinkages. After mixing, the composite slurry is poured in a preheated mould and reach room temperature. Casted composite fabricated by stir casting displays in Fig. 3. After preparing A17075/6wt.\%SiC aluminium matrix composites fabricated by stir casting, the sectioned specimen was cut and the surface polished up to mirror finish by using consecutively 400, 600, 800, 1000, 1500 and 2000 graded emery paper and also polished with $0.1 \mu \mathrm{m}$ diamond paste. The composite specimen was etched by Keller's reactant (solution of $2 \mathrm{ml} \mathrm{HF}, 3 \mathrm{ml} \mathrm{HCL}, 5 \mathrm{ml} \mathrm{HNO} 3$ and $190 \mathrm{ml}$ $\mathrm{H}_{2} \mathrm{O}$ ). Microstructural analyses were used to observe the microstructural evaluation of aluminium matrix composites and the distribution of the reinforced particulates of silicon carbide throughout the aluminium matrices. Pin-on-disc dry sliding wear runs were done in 
DUCOM's, TR 20LE-M5 depicts in Fig. 4. Casted specimens were machined to organize 6 $\mathrm{mm}$ diameter and $40 \mathrm{~mm}$ gauge length pins as per ASTM G99 standard that rubbed within the counter friction plate EN31 steel disc which having hardness is $62 \mathrm{HRC}$.
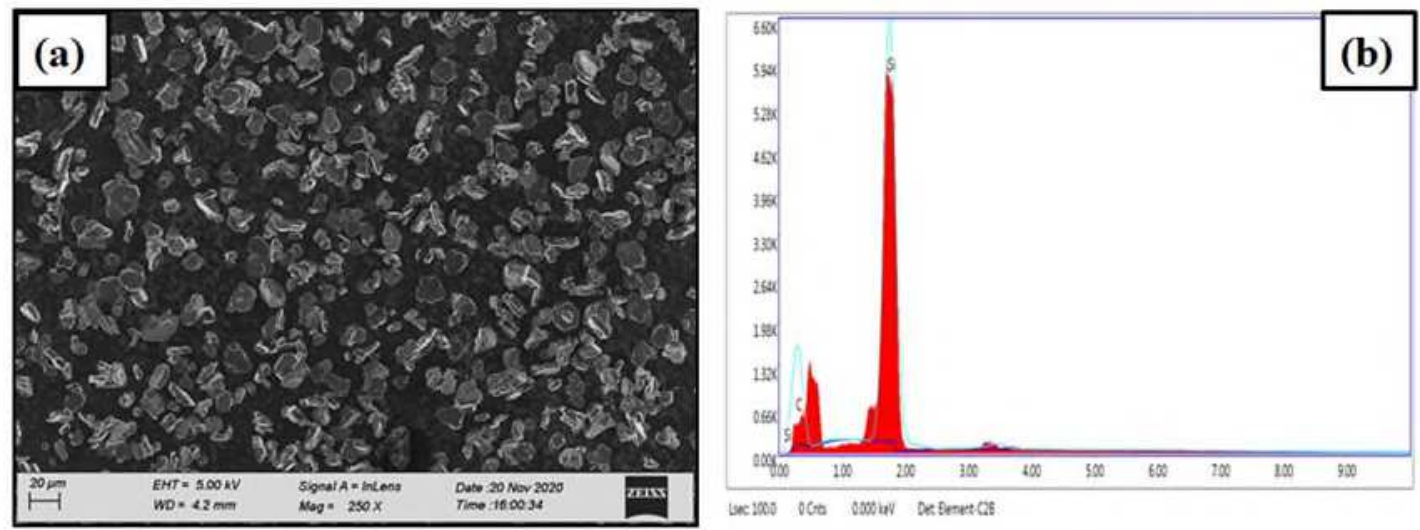

Fig. 1 (a) Micrograph and (b) EDX of SiC ceramic particles

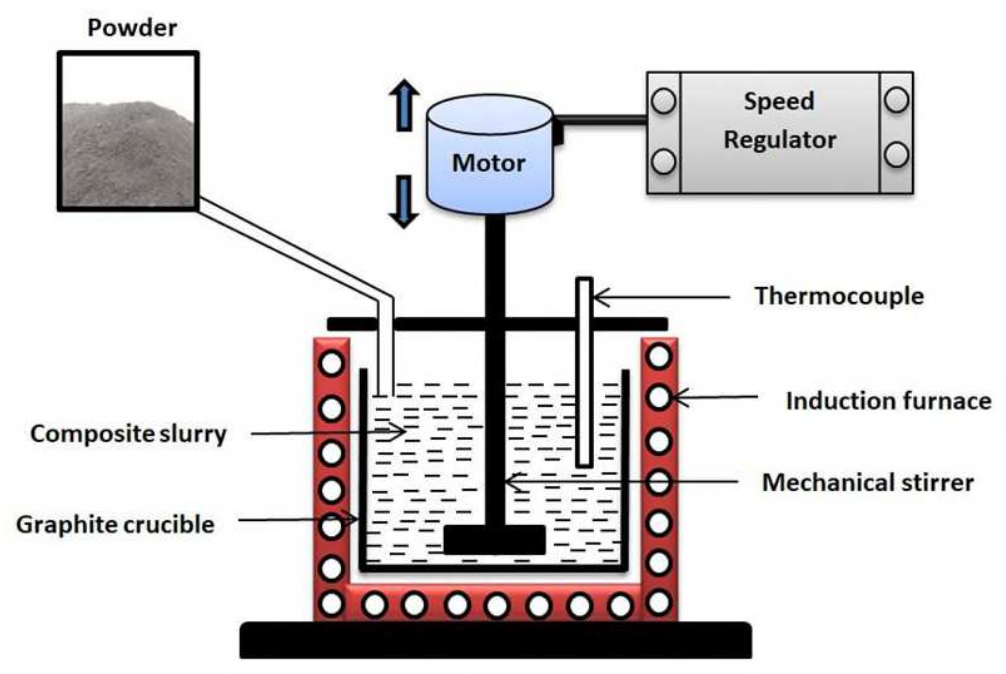

Fig. 2 Schematic representation of stir casting fabrication setup

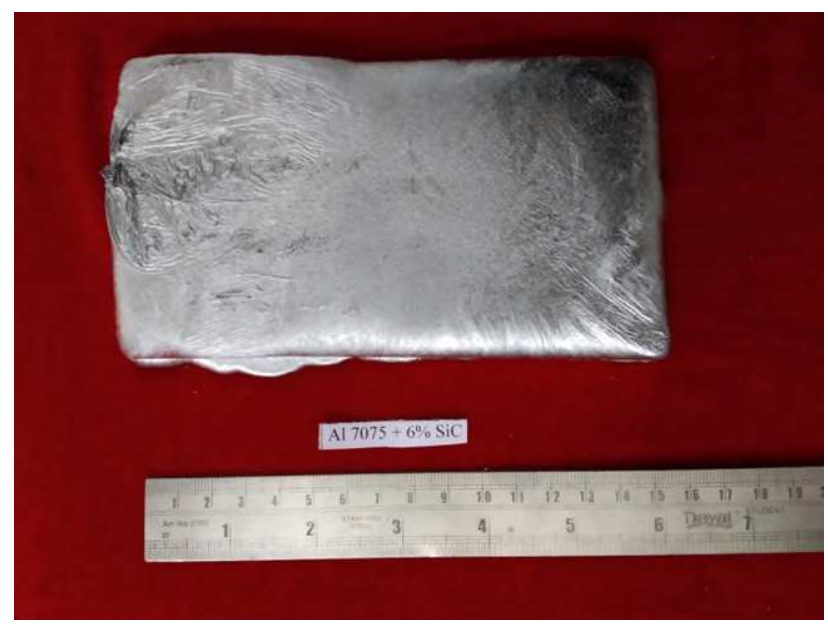

Fig. 3 Casted composite fabricated by stir casting 


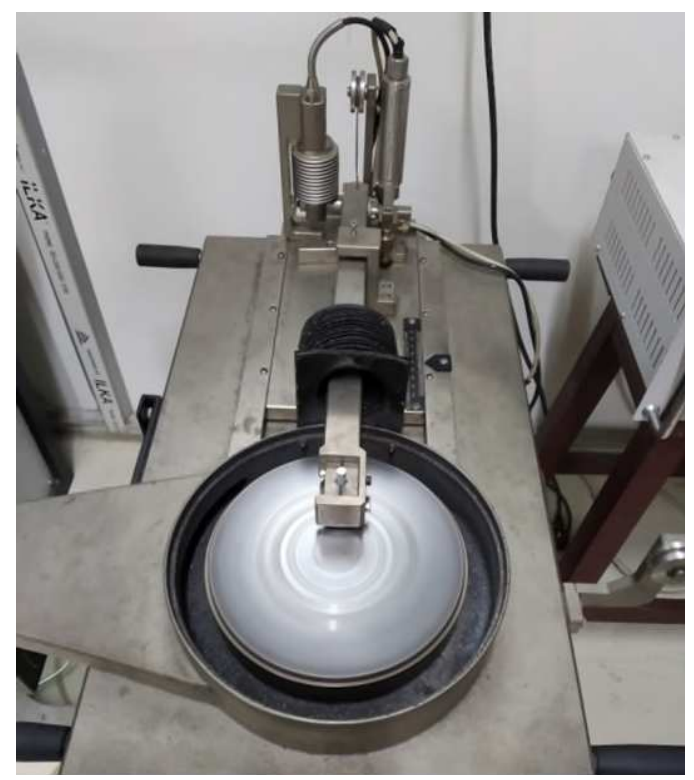

Fig. 4 Pin on Disc wear setup (DUCOM's, TR 20LE-M5)

\subsection{Design of Experiment}

Taguchi's ideology is a powerful tool to optimize the pattern of superior quality aspects. Dr. Genichi Taguchi was invented this technique depend on orthogonal array experiments, which introduce minimum deviation for the experiment with optimal factor setting. Therefore, the combination of the design of experiments according to the optimal combination of the process to acquire appropriate results is established in the Taguchi technique. Based on previous literature [27-29], it is observed that the load, sliding speed and sliding distance was recognized best process parameters for wear test and assorted with four different levels of each factor shown in Table 1. Putting load quantity (10, 20, 30 and 40 Newton) were chosen depending on earlier research output to found the influence on the wear rate of casted material. Sliding speed levels $(0.5,1,1.5$ and 2 metre/second) were chosen because of the shelter of the friction plane that preserved by the oxide layer. At 3 metre/second sliding speed, the contact period in between contact planes are very low that produced wide oxide layer. Sliding distance levels (500, 1000, 1500 and 2000 metre) chosen because of the highest limitation of sliding distance was retain $2000 \mathrm{~m}$ due to the wear testing machine limitations and after $2000 \mathrm{~m}$ sliding distance shown a steady graph. For precision, take four specimens wont to measure for every input parameter and make the typical value. This work has been conducted by Taguchi's DOE to decrease the total number of runs. For minimizing the number of experimental runs for 3 parameters and their 4 levels, Taguchi's $\mathrm{L}_{16}$ orthogonal array used shows in Table 2. Frictional force responses are collected from machine data. Wear rate and coefficient of friction for sample pin were measured by Eq. 1 and 2 as used earlier [30, 31].

$$
\begin{aligned}
\text { Wear rate }\left(\mathrm{mm}^{3} / \mathrm{m}\right) & =\frac{\text { Volumetric Loss }}{\text { Sliding Distance }} \\
\text { Coefficient of Friction }(\mu) & =\frac{\text { Frictional Force }}{\text { Applied Load }}
\end{aligned}
$$


Table 1 Process parameters and their four different levels

\begin{tabular}{ccccccc}
\hline Parameters & Notation & Units & \multicolumn{4}{c}{ Level } \\
\cline { 4 - 7 } & & & $\mathbf{1}$ & $\mathbf{2}$ & $\mathbf{3}$ & $\mathbf{4}$ \\
\hline Load & $\mathrm{L}$ & $\mathrm{N}$ & 10 & 20 & 30 & 40 \\
Sliding Speed & $\mathrm{S}$ & $\mathrm{m} / \mathrm{s}$ & 0.5 & 1 & 1.5 & 2 \\
Sliding Distance & $\mathrm{D}$ & $\mathrm{m}$ & 500 & 1000 & 1500 & 2000 \\
\hline
\end{tabular}

Table 2 Measured experimental data related to three input process parameters

\begin{tabular}{|c|c|c|c|c|c|c|}
\hline \multirow{2}{*}{$\begin{array}{c}\text { Sl. } \\
\text { No. }\end{array}$} & \multicolumn{3}{|c|}{ Input parameters } & \multicolumn{3}{c|}{ Output responses } \\
\cline { 2 - 7 } & $\begin{array}{c}\text { Load } \\
(\mathbf{N})\end{array}$ & $\begin{array}{c}\text { Sliding } \\
\text { Speed } \\
(\mathbf{m} / \mathbf{s})\end{array}$ & $\begin{array}{c}\text { Sliding } \\
\text { Distance }(\mathbf{m})\end{array}$ & $\begin{array}{c}\text { Wear rate } \\
\left(\mathbf{m m}^{3} / \mathbf{m}\right)\end{array}$ & $\begin{array}{c}\text { Friction } \\
\text { force } \\
(\mathbf{N})\end{array}$ & $\begin{array}{c}\text { COF } \\
(\boldsymbol{\mu})\end{array}$ \\
\hline 1 & 10 & 0.5 & 500 & 0.00392 & 1.43 & 0.143 \\
\hline 2 & 10 & 1 & 1000 & 0.00454 & 1.42 & 0.142 \\
\hline 3 & 10 & 1.5 & 1500 & 0.00485 & 1.32 & 0.132 \\
\hline 4 & 10 & 2 & 2000 & 0.00573 & 1.11 & 0.111 \\
\hline 5 & 20 & 0.5 & 1000 & 0.00512 & 4.3 & 0.215 \\
\hline 6 & 20 & 1 & 500 & 0.00514 & 3.18 & 0.159 \\
\hline 7 & 20 & 1.5 & 2000 & 0.00576 & 3.56 & 0.178 \\
\hline 8 & 20 & 2 & 1500 & 0.00624 & 3.12 & 0.156 \\
\hline 9 & 30 & 0.5 & 1500 & 0.00591 & 8.04 & 0.268 \\
\hline 10 & 30 & 1 & 2000 & 0.00668 & 6.93 & 0.231 \\
\hline 11 & 30 & 1.5 & 500 & 0.00621 & 5.64 & 0.188 \\
\hline 12 & 30 & 2 & 1000 & 0.00684 & 5.16 & 0.172 \\
\hline 13 & 40 & 0.5 & 2000 & 0.00694 & 14.04 & 0.351 \\
\hline 14 & 40 & 1 & 1500 & 0.00697 & 12.48 & 0.312 \\
\hline 15 & 40 & 1.5 & 1000 & 0.00735 & 11.16 & 0.279 \\
\hline 16 & 40 & 2 & 500 & 0.00758 & 7.84 & 0.196 \\
\hline
\end{tabular}

\subsection{Grey Relational Analysis (GRA)}

According to grey relational analysis, measured readings of response characteristics are being normalized ranging from 0 to 1 . This method called grey relational generation. After normalization, determine the grey relational coefficient to interconnect in between different factors and their multiple levels. Next, find the overall grey relational grade by determining the mean value of the grey relational coefficient. These 3 steps converted multi-objective optimization to single-objective optimization [32, 33]. The optimal factor setting then analyzes the maximum grey relational grade by applying the Taguchi method. 


\section{Step-1}

Output raw data have been normalized first (Grey Relational Generation) by using Eq. 3 and Eq. 4 described below [34]. The normalized results for all factors related to wear analysis have been furnished. In this experiment, all responses or outputs such as wear rate, friction force and $\mathrm{COF}$ are applicable for smaller is better criterion.

$$
\begin{aligned}
\alpha_{i}^{*}(\chi) & =\frac{y_{i}(m)-\min y_{i}(m)}{\max y_{i}(m)-\min y_{i}(m)} \quad \text { (Larger is Better) } \\
\alpha_{i}^{*}(\chi) & =\frac{\max y_{i}(m)-y_{i}(m)}{\max y_{i}(m)-\min y_{i}(m)} \quad \text { (Smaller is Better) }
\end{aligned}
$$

Where, $\mathrm{i}=1$ to $\mathrm{p}$ and $\mathrm{m}=1$ to $\mathrm{k}$; $\mathrm{p}$ represents all experimental runs and $\mathrm{k}$ represents the total number of process parameters. $y_{i}(m)$ represents the original response; $\max y_{i}(m)$ and $\min y_{i}(m)$ represent the maximum and minimum result of original output result and $\alpha_{i}^{*}(m)$ denotes the normalized value after calculating output result attributes.

\section{Step-2}

Grey Relational Coefficient (GRC) for all responses of Taguchi's $\mathrm{L}_{16}$ orthogonal array after data processing or normalizing is calculated by Eq. 5 described below [35].

$\varepsilon_{\mathrm{i}}(\mathrm{k})=\frac{\Delta_{\min }+\eta \Delta_{\max }}{\Delta_{0 \mathrm{i}}(\mathrm{j})+\eta \Delta_{\max }}$

Where, $\Delta_{0 \mathrm{i}}(\mathrm{j})$ represents the variation of the original responses and $\eta$ represents the differentiate coefficient $0 \leq \eta \leq 1$ and is generally chosen 0.5 because of the equal weightage specified in all factors. $\Delta_{\min }$ and $\Delta_{\max }$ represent the minimum and maximum value of data preparing responses.

\section{Step-3}

Grey relational coefficient for every value has been collected for analyzing Grey Relational Grade (GRG) that indicates the overall characteristics of wear behaviour. Thus grey relational analysis generally performs for converting single objective optimization from a multiobjective optimization problem [36]. The maximum values of GRG are too closer to the optimized parameter combination. Grey relational grade lies between 0 and 1 . Grey relational grade for all responses of Taguchi's $\mathrm{L}_{16}$ orthogonal array after data processing is calculated by Eq. 6.

$$
\mathrm{\gamma}_{\mathrm{i}}=\frac{1}{\mathrm{~m}} \sum_{\mathrm{k}=1}^{\mathrm{n}} \varepsilon_{\mathrm{i}}(\mathrm{k})
$$

Where $\gamma_{\mathrm{i}}$ represents the overall GRG; $\mathrm{m}$ is the total number of output results; $\varepsilon_{\mathrm{i}}(\mathrm{k})$ represents each response value of GRC. 


\subsection{Fuzzy Interface System}

Fuzzy logic contains various steps includes fuzzification of input data, fuzzy rule interface, and defuzzification of crisp value [37, 38]. In this study, Grey Relational Coefficient (GRC) values are fuzzified using fuzzifier applying membership functions [39]. Steps includes greyfuzzy approach depicts in Fig. 5. After that fuzzy interface engine executes a fuzzy interface to form fuzzy rules for single fuzzy value instead of three various GRC values. At last, the defuzzifier transforms this single fuzzy value move into GFG.

Initially, input response characteristics of GRC values transform into a rhetorical fuzzy set. Triangle type membership functions are applied at the time of fuzzification of three various GRC values by applying small (S), medium (M), and large (L) fuzzy subsets. By applying triangle type membership functions fuzzifier fuzzified grey relational coefficient dataset ranges into 0 and 1.

Response characteristics of fuzzy interference method are a fuzzy grade ranges 0 to 1 , which transformed by using triangle type membership functions into the rhetorical fuzzy subset depicts in Fig. 6. Seven various sorts of subsets are allocated for output results viz. very very low (VVL), very low (VL), low $(\mathrm{L})$, medium $(\mathrm{M})$, large $(\mathrm{H})$, very large $(\mathrm{VH})$ and very very large (VVH). Fig. 7 displays the quantity of fuzzy rule executed during this controller.

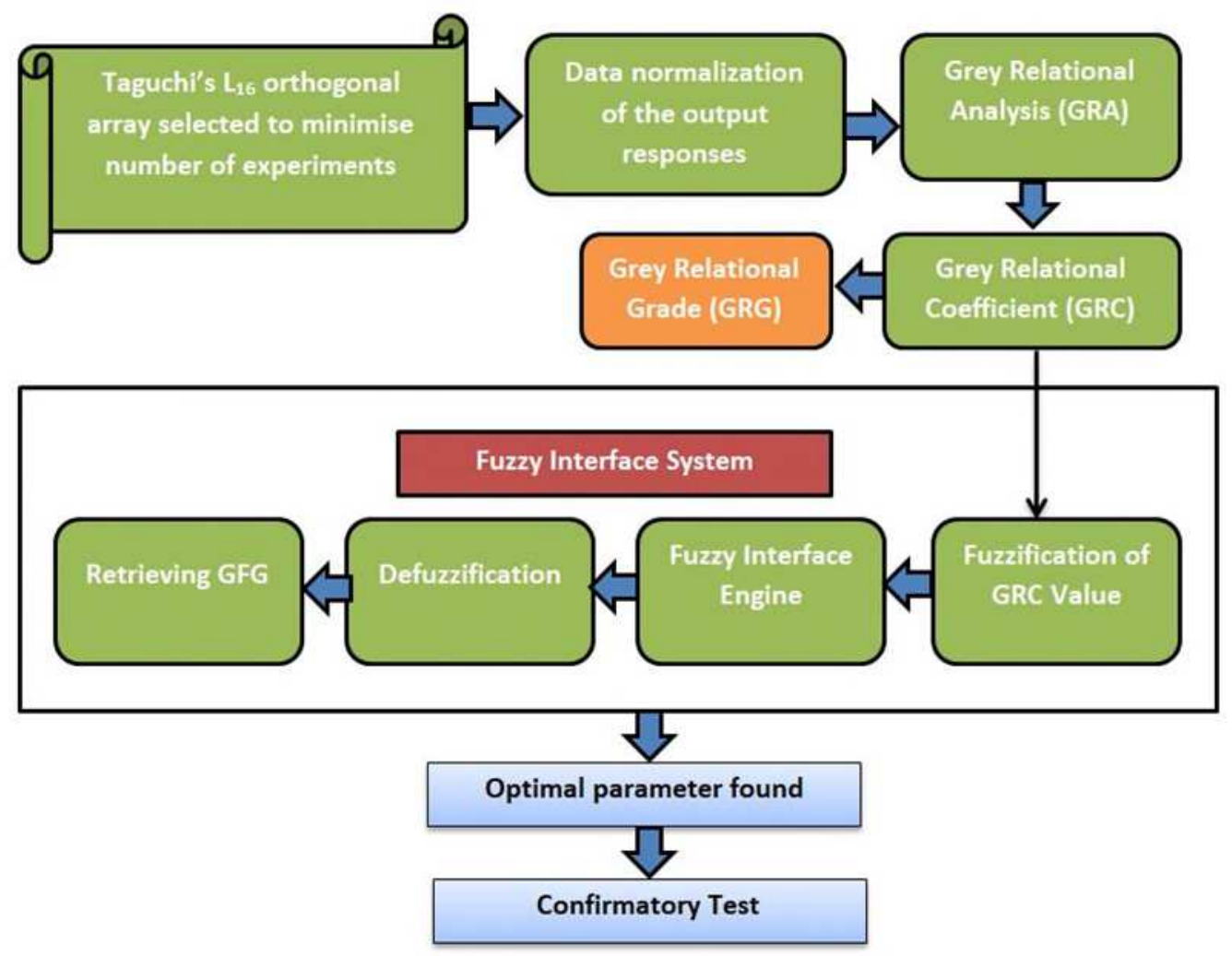

Fig. 5 Steps include grey-fuzzy approach 


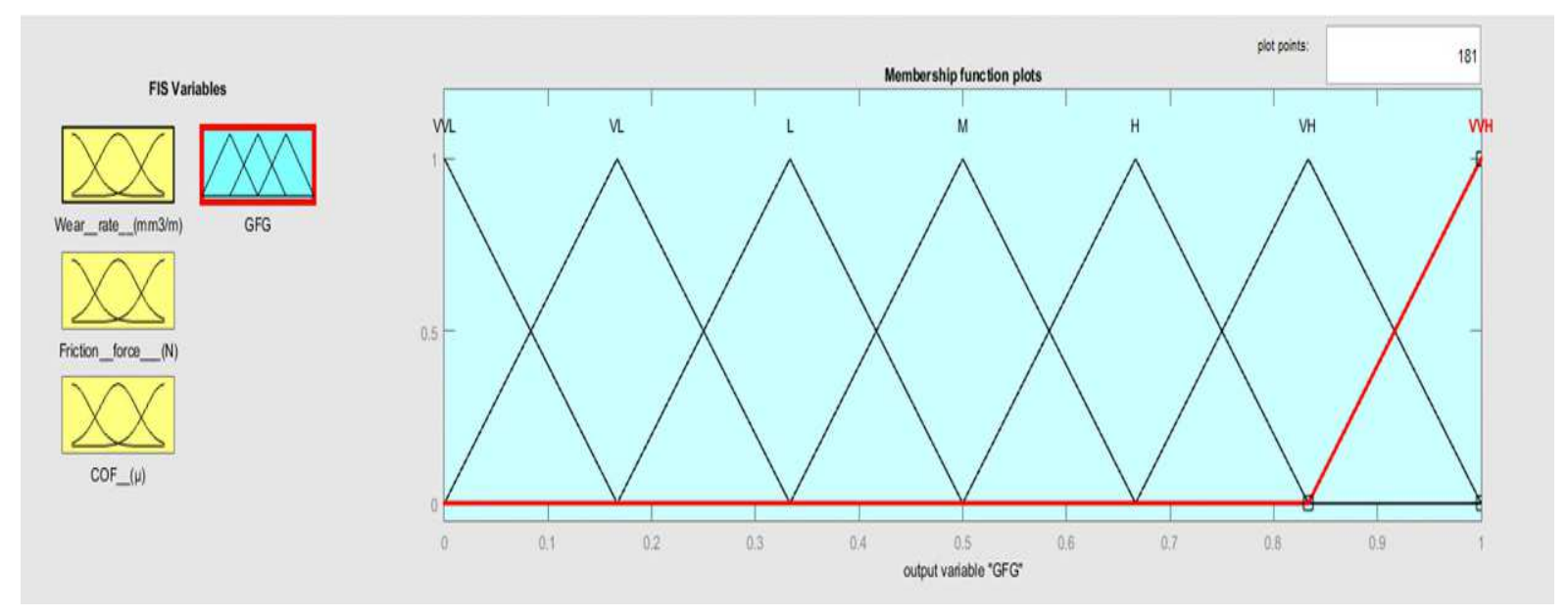

Fig. 6 Structure of seven fuzzy subsets for GFG

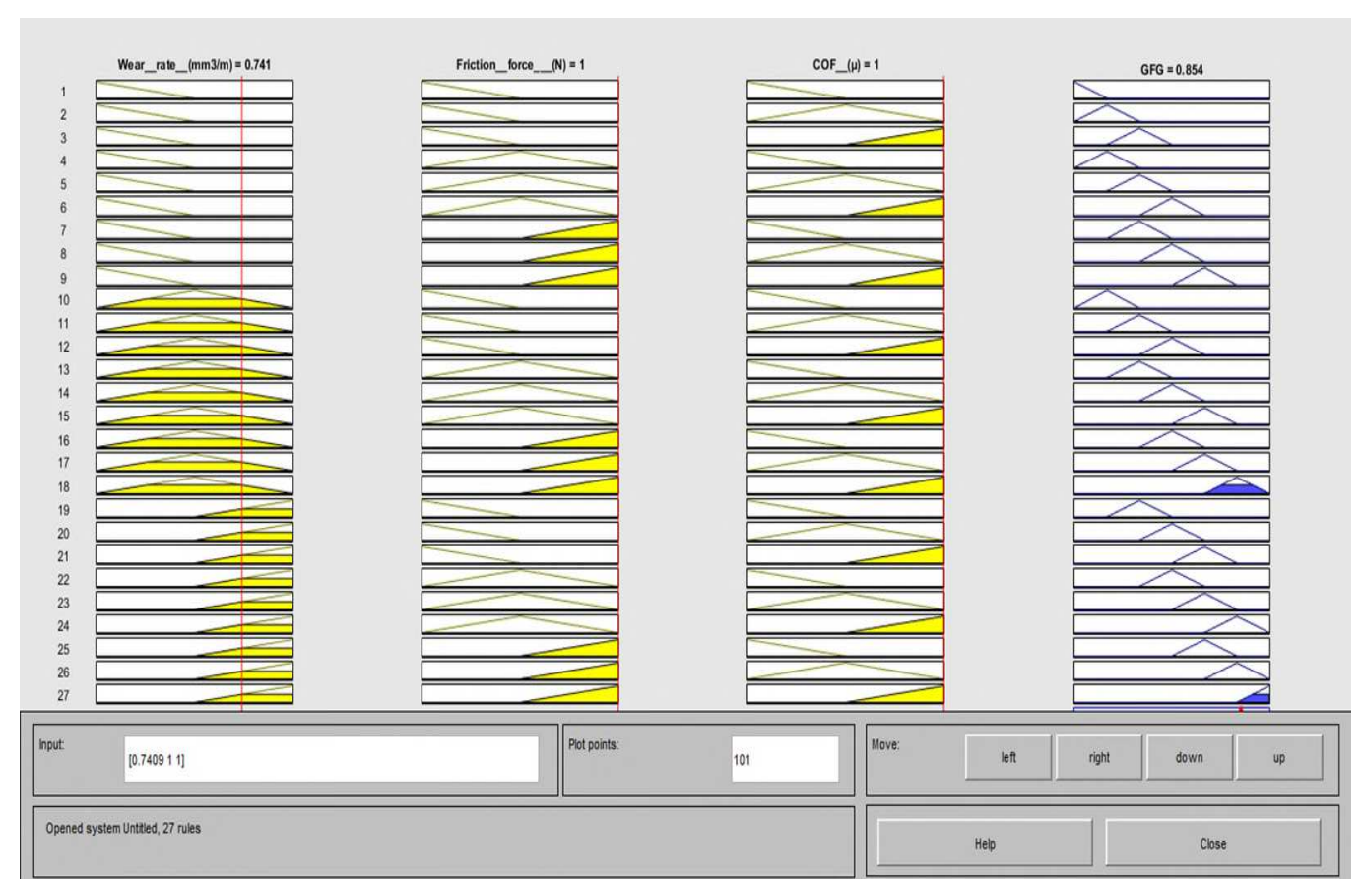

Fig. 7 Fuzzy logic membership function for GFG

According to the fuzzy rule, IF-THEN rules are wont to prepare the boundary report. Fuzzy rule retains a gaggle of IF-THEN formula by applying 81 several sorts of fuzzy logic that describes below,

Rule 1: If $\alpha_{1}$ is $\mathrm{E} 1$ and $\alpha_{2}$ is $\mathrm{F} 1$ and $\alpha_{3}$ is $\mathrm{G} 1$ then $\mathrm{k}$ is $\mathrm{H} 1$ else

Rule 2: If $\alpha_{1}$ is $\mathrm{E} 2$ and $\alpha_{2}$ is $\mathrm{F} 2$ and $\alpha_{3}$ is $\mathrm{G} 2$ then $\mathrm{k}$ is $\mathrm{H} 2$ else

Rule n: If $\alpha_{1}$ is En and $\alpha_{2}$ is Fn and $\alpha_{3}$ is Gn then $\mathrm{k}$ is Hn else

Where, $\alpha_{1}, \alpha_{2}$, and $\alpha_{3}$ are input values of fuzzy logic. En, Fn, Gn and Hn are different fuzzy subsets and $k$ represents output results. These $E_{x}, F_{x}, G_{x}$ and $H_{x}$ are fuzzy subsets described 
by the denoting membership functions, viz. $\mu \mathrm{E}_{\mathrm{x}}, \mu \mathrm{F}_{\mathrm{x}}, \mu \mathrm{G}_{\mathrm{x}}$, and $\mu \mathrm{H}_{\mathrm{x}}$. Multi-objective response fuzzy values alongside membership function denoted as,

$$
\mu D_{i}\left(y_{i}\right)=\operatorname{Max}\left[\operatorname{Min}_{j}\left\{\mu E \alpha_{1}\left(\alpha_{1}\right), \mu E \alpha_{2}\left(\alpha_{2}\right), \mu E \alpha_{3}\left(\alpha_{3}\right) \ldots \ldots \ldots \ldots . . . \mu E \alpha_{n}\left(\alpha_{n}\right)\right\}\right]
$$

After that defuzzification process obtained here to form fuzzy interference output $\mu D_{i}\left(y_{i}\right)$ [40] into an un-fuzzy value $\mathrm{y}^{\mathrm{k}}$,

$\mathrm{y}^{\mathrm{k}}=\frac{\int y_{i} \mu \mathrm{Di}\left(y_{i}\right) d y}{\int \mu \mathrm{Di}\left(y_{i}\right) d y}$

A wider grey fuzzy grade of the upper un-fuzzy value $\mathrm{y}^{\mathrm{k}}$ gives excellent results.

\section{Results and Discussion}

\subsection{SEM and EDX analysis}

Microstructural analysis of Al7075/6wt.\%SiC composite conducted by Scanning Electron Microscope (Model - Sigma 300, Carl Zeiss) depicts in Fig. 8(a). The solidification process regulates the dispersal of SiC particles in Al7075 matrices. The density difference between the matrix material and reinforcement particles plays a vital role at the stage of solidification. If the reinforcement particle is denser than aluminium matrix then start to submerged in the melt and vice versa. Microstructure reveals that silicon carbide particles homogeneously distributed throughout the matrix material that obtained better mechanical bonding between matrix and reinforcement due to hard and rigid $\mathrm{SiC}$ particles induce shear stress in the melt that boosts split up and mixing homogenization. EDX (Energy Dispersion X-ray spectroscopy) result of aluminium matrix composite reinforced with silicon carbide micro particles is shown in Fig. 8(b). EDX analysis identified some major elements are Al, Si, C, $\mathrm{Cr}, \mathrm{Fe}, \mathrm{Mg}, \mathrm{Cu}$ and $\mathrm{Zn}$. EDX spectra curves of $\mathrm{SiC}$ reinforced composite indicated the peaks of $\mathrm{Si}$ and $\mathrm{C}$ that revealed the existence of reinforcement particles in the matrix. EDX basically detects the atomic and weight percentile of each and every element that present in composite and identified by the formation of peaks.

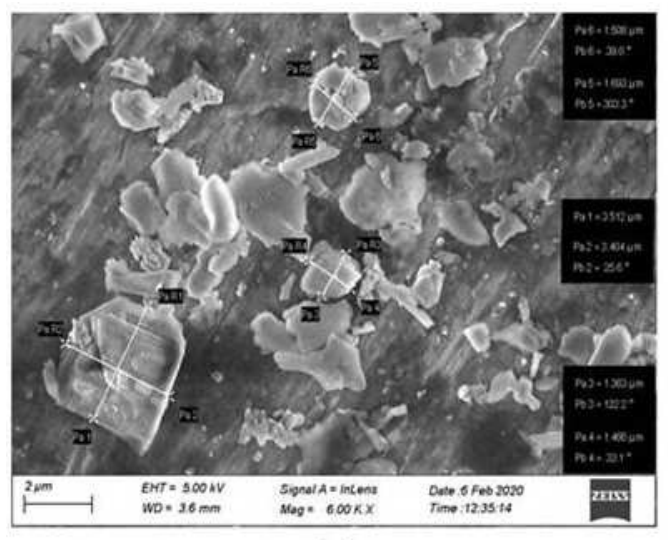

(a)

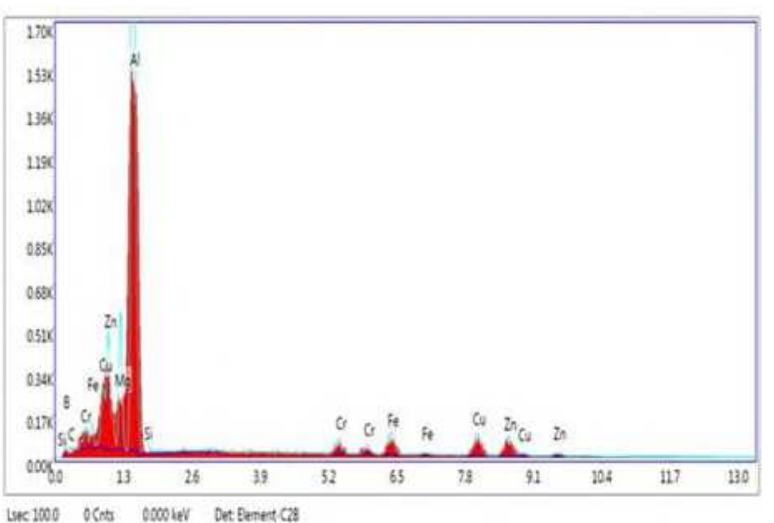

(b)

Fig. 8 (a) SEM microscopic structure and (b) EDX spectra curves of Al7075/6wt.\% SiC 


\subsection{Grey-Fuzzy relational analysis}

Matlab statistical software used to treat the Grey-Fuzzy technique for occurring grey fuzzy relational grade. Clarified grey fuzzy grade developed by using the Fuzzy technique. Developed GFG response with minimum untrustworthy has been observed in between fuzzy rule and GRA. Grey relational results using fuzzy make a better qualitative result as compared to plain GRA. By applying Eq. 3 and 5, GRA and GRG value for all responses are determined displays in Table 3. Triangle type membership functions along 3 fuzzy subsets for grey relational coefficient and seven fuzzy subsets for response grey relational grade is applied. GFG values of all experiments and their rank displays in Table 4. The variation of GRG and GFG value for all experimental runs are shown in Fig. 9. By matching Table $3 \& 4$, an modern grading with minimum unpredictability observed for each samples. The main effects on the input parameters of GFG are displays in Table 5. Delta value represents the deviation between the maximum and minimum values. From the main effect plot depicts in Fig.10, the optimal process control factors has been found. The optimal parameter setting for maximum grey fuzzy grade becomes $\mathrm{L}_{1} \mathrm{~S}_{4} \mathrm{D}_{1}(10 \mathrm{~N}$ load, $2 \mathrm{~m} / \mathrm{s}$ sliding speed, and $500 \mathrm{~m}$ sliding distance). According to Table 4, it is conclude that sample number 13 was ranked first with maximum GFG value of 0.854 .

Table 3 Overview of GRC and GRG for particular response

\begin{tabular}{cccccc}
\hline $\begin{array}{c}\text { Sample } \\
\text { No. }\end{array}$ & $\begin{array}{c}\text { GRC (Wear } \\
\text { rate) }\end{array}$ & $\begin{array}{c}\text { GRC (Friction } \\
\text { force) }\end{array}$ & GRC (COF) & GRG & Rank \\
\hline 1 & 0.333333 & 0.338925 & 0.365854 & 0.34603743 & 16 \\
2 & 0.37577 & 0.338748 & 0.364742 & 0.35975312 & 15 \\
3 & 0.401316 & 0.336982 & 0.353982 & 0.36409337 & 14 \\
4 & 0.497283 & 0.333333 & 0.333333 & 0.38798309 & 13 \\
5 & 0.426573 & 0.398951 & 0.46875 & 0.43142479 & 10 \\
6 & 0.428571 & 0.37316 & 0.384615 & 0.395449 & 12 \\
7 & 0.50137 & 0.381528 & 0.409556 & 0.43081822 & 11 \\
8 & 0.577287 & 0.371872 & 0.380952 & 0.44337058 & 9 \\
9 & 0.522857 & 0.518652 & 0.591133 & 0.54421412 & 6 \\
10 & 0.67033 & 0.476243 & 0.5 & 0.54885759 & 5 \\
11 & 0.571875 & 0.434914 & 0.424028 & 0.47693917 & 8 \\
12 & 0.712062 & 0.42131 & 0.401338 & 0.51156997 & 7 \\
$\mathbf{1 3}$ & $\mathbf{0 . 7 4 0 8 9 1}$ & $\mathbf{1}$ & $\mathbf{1}$ & $\mathbf{0 . 9 1 3 6 3 0 2 3}$ & $\mathbf{1}$ \\
14 & 0.75 & 0.805607 & 0.754717 & 0.77010815 & 2 \\
15 & 0.88835 & 0.691814 & 0.625 & 0.73505444 & 3 \\
16 & 1 & 0.510462 & 0.436364 & 0.64894185 & 4 \\
\hline
\end{tabular}


Table 4 GFG and their particular rank for each factor

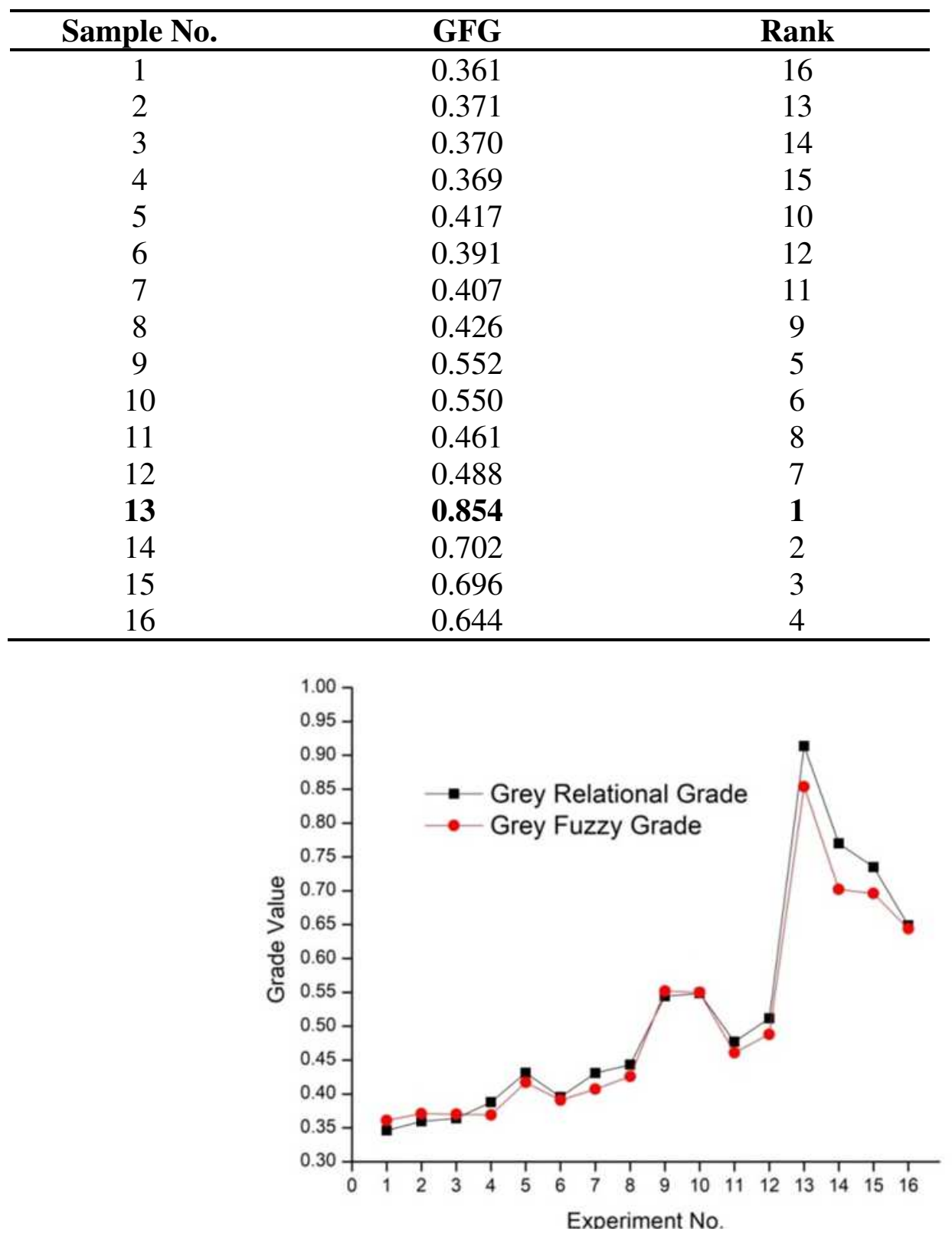

Fig. 9 Compare in between GRG and GFG

Table 5 Response table on grey fuzzy grade (Smaller is better)

\begin{tabular}{cccc}
\hline Level & Load & Sliding Speed & Sliding Distance \\
\hline 1 & 8.689 & 5.745 & 6.889 \\
2 & 7.743 & 6.259 & 6.397 \\
3 & 5.828 & 6.579 & 6.071 \\
4 & 2.854 & 6.531 & 5.758 \\
Delta & 5.836 & 0.835 & 1.13 \\
Rank & 1 & 3 & 2 \\
\hline
\end{tabular}




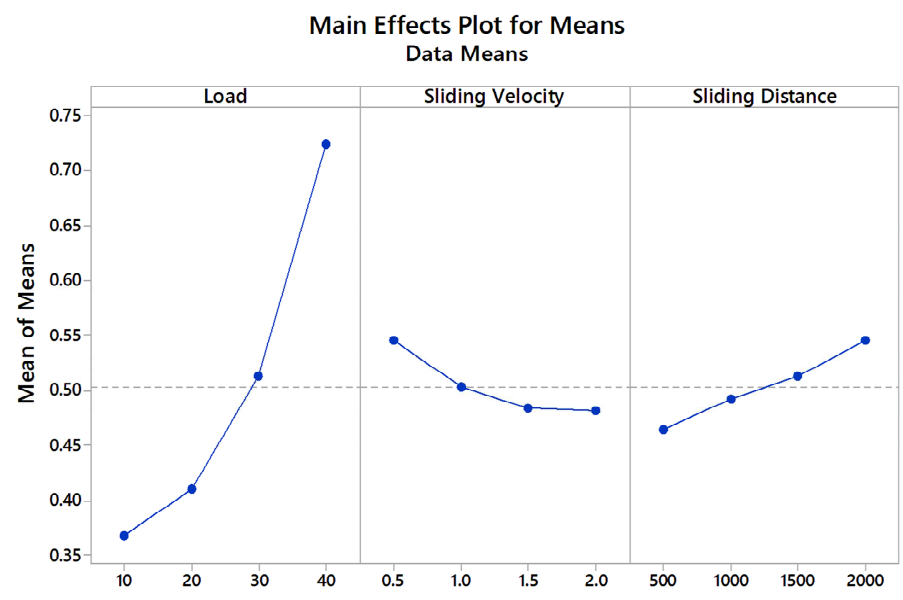

Fig. 10 Response graph plot for GFG

\subsection{ANOVA}

The objective of ANOVA is to determine the significant factor from the design of experiment control parameters. Table 6 represents the ANOVA (Analysis of Variance) analysis for GFG. ANOVA is a arithmetical tool which can be applied to identify factors impact. It is noticed that the probability (p) value for load is 0.027 which is lower than 0.05 . So it is obvious that load is the only significant factor. R-sq and R-sq(adj) value were $99.11 \%$ and $97.77 \%$ respectively which very closer to unity which means the model equation was better fitted with the actual value.

Table 6 Analysis of Variance (ANOVA) for grey fuzzy grade

\begin{tabular}{|c|c|c|c|c|c|c|}
\hline Source & DF & Adj SS & Adj MS & F & p & Remarks \\
\hline Load & 1 & 0.004223 & 0.004223 & 8.48 & 0.027 & Significant \\
\hline Sliding Velocity & 1 & 0.000001 & 0.000001 & 0 & 0.965 & Insignificant \\
\hline Sliding Distance & 1 & 0.000006 & 0.000006 & 0.01 & 0.914 & Insignificant \\
\hline Load×Load & 1 & 0.028477 & 0.028477 & 57.18 & 0.000 & Significant \\
\hline $\begin{array}{c}\text { Sliding Velocity } \\
\times \text { Sliding Velocity }\end{array}$ & 1 & 0.001661 & 0.001661 & 3.33 & 0.118 & Insignificant \\
\hline $\begin{array}{c}\text { Sliding Distance } \\
\times \text { Sliding Distance }\end{array}$ & 1 & 0.000014 & 0.000014 & 0.03 & 0.872 & Insignificant \\
\hline $\begin{array}{c}\text { Load×Sliding } \\
\text { Velocity }\end{array}$ & 1 & 0.001231 & 0.001231 & 2.47 & 0.167 & Insignificant \\
\hline $\begin{array}{c}\text { Load } \times \text { Sliding } \\
\text { Distance }\end{array}$ & 1 & 0.002399 & 0.002399 & 4.82 & 0.071 & Insignificant \\
\hline $\begin{array}{c}\text { Sliding Velocity } \\
\times \text { Sliding Distance }\end{array}$ & 1 & 0.000951 & 0.000951 & 1.91 & 0.216 & Insignificant \\
\hline Error & 6 & 0.002988 & 0.000498 & & & \\
\hline Total & 15 & 0.334841 & & & & \\
\hline
\end{tabular}

$\mathrm{S}=0.0223154 ; \mathrm{R}-\mathrm{Sq}=99.11 \% ;$ and $\mathrm{R}-\mathrm{Sq}(\operatorname{adj})=97.77 \%$.

Where, $\mathrm{DF}=$ Degree of freedom, Adj SS= Adjacent sum of squares, Adj MS= Adjacent mean squares, $F=$ Variance, $p=$ Probability 


\subsection{Regression analysis}

Predicted grey fuzzy grade as per stipulated levels of factors by applying regression analysis, a quadratic polynomial regression equation for grey fuzzy grade shown in Eq. 9.

$\mathrm{GFG}=0.4423-0.01149 \mathrm{~L}-0.0036 \mathrm{~S}-0.000009 \mathrm{D}+0.000422(\mathrm{~L} \times \mathrm{L})+0.0407(\mathrm{~S} \times \mathrm{S})$

$+0.000000(\mathrm{D} \times \mathrm{D})-0.00237(\mathrm{~L} \times \mathrm{S})+0.000003(\mathrm{~L} \times \mathrm{D})-0.000042(\mathrm{~S} \times \mathrm{D})$

Where, $\mathrm{L}$ is load in $\mathrm{N}, \mathrm{S}$ is sliding velocity in $\mathrm{m} / \mathrm{s}$ and $\mathrm{D}$ is sliding distance in $\mathrm{m}$.

Adequacy of the model was executed by the residual plot of grey fuzzy grade depict in Fig. 11. Variation in between estimated value and equivalence fitted result represent as residual. It is usually used to check model fitting or not. Normal probability plot displays every response closely fitted during a line. Versus fits was shown the formed regression model was closefitted. Histogram and versus order shown that the residual points are distributed on the specific side.

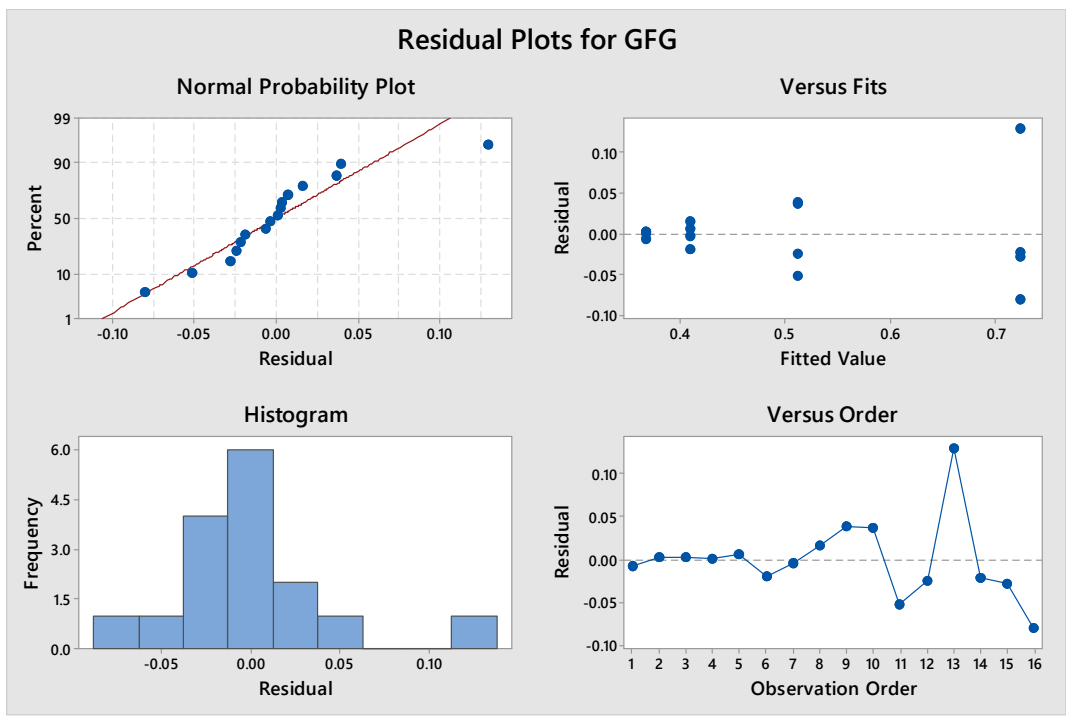

Fig. 11 Residual plot of grey fuzzy grade

\subsection{Confirmatory Test}

Optimized estimated result of GFG ( $\left.y_{\text {Predicted }}\right)$ is measured [41] by using Eq. 10 are as follows.

$$
y_{\text {Predicted }}=y_{m}+\sum_{i=1}^{n}\left(y_{i}-y_{m}\right)
$$

Where $y_{m}$ is the mean result of grey fuzzy grade, $y_{i}$ is the mean of the optimized value of grey fuzzy grade, and " $n$ " is the number of parameters.

A confirmatory test was performed on the optimal process parameter combination of $\mathrm{L}_{1} \mathrm{~S}_{4} \mathrm{D}_{1}$ found on MINITAB statistical tool. The experimental value of the grey fuzzy grade for the optimized parameter combination is lower than the predicted value. A minor percentage error of $2.79 \%$ is acquired between the predicted and experimental value that impacts a good correlation shown in Table 7. 
Table 7 Confirmatory test result for wear rate

\begin{tabular}{cccc}
\hline & \multicolumn{2}{c}{ Optimized parameter } & \multirow{2}{*}{ Error (\%) } \\
\cline { 2 - 3 } & Predicted Result & $\begin{array}{c}\text { Experimental } \\
\text { Result }\end{array}$ & \\
\hline Level & $\mathrm{L}_{1} \mathrm{~S}_{4} \mathrm{D}_{1}$ & $\mathrm{~L}_{1} \mathrm{~S}_{4} \mathrm{D}_{1}$ & 2.79 \\
GFG & 0.8076 & 0.7851 & \\
\hline
\end{tabular}

\subsection{Worn surface morphology}

Worn micrographs of A17075/6wt.\%SiC composite collected from the unlubricated wear test examined by field emission scanning electron microscope. The impact of variation on applied load with different sliding distance and constant sliding speed on the pin surface is required to study and also it has great importance for analyzing wear characteristics depicts in Fig.12(a-d). Fig. 12 (a) and (c) depicts several plastic deformations due to the formation of parallel deep grooves. Stress generated during rubbing has maximum sharp edges at higher loads that form cracks in the pin surface. From the worn surface analysis, it's perceived that a slicker layer of pin surface produced with enhancing applied load. As it is seen in Fig.12(a-d), asperities of pin surface make deformed shape at maximum load and formation of the smooth contact layer and due to continuous sliding process, a huge amount of heat form in between the sliding contacts that generate tribo oxide layer [42]. The microstructure of worn surface of Al7075/6wt.\%SiC composite at 40N applied load with the variation of sliding speed and sliding distance depicts in Fig.12(d-f). Fig. 12(f) shows the formation of a mechanically mixed layer and shallow grooves that indicates maximum material removal because of more heat formation and maximum sliding speed. Mechanically mixed layer generally forms due to the combination of oxide surface just after the crucial plastic deformation of pin contact surface at very high temperature and it is occurred due to high sliding speed [27]. Fig. 12(d) and 12(e) identified the ploughing effect and smaller grooves that generally form due to stiffness of reinforcement particulates. Smaller grooves show the minimum material removal because of the low pressure generated between the pin surface and counter disc plate [43]. 

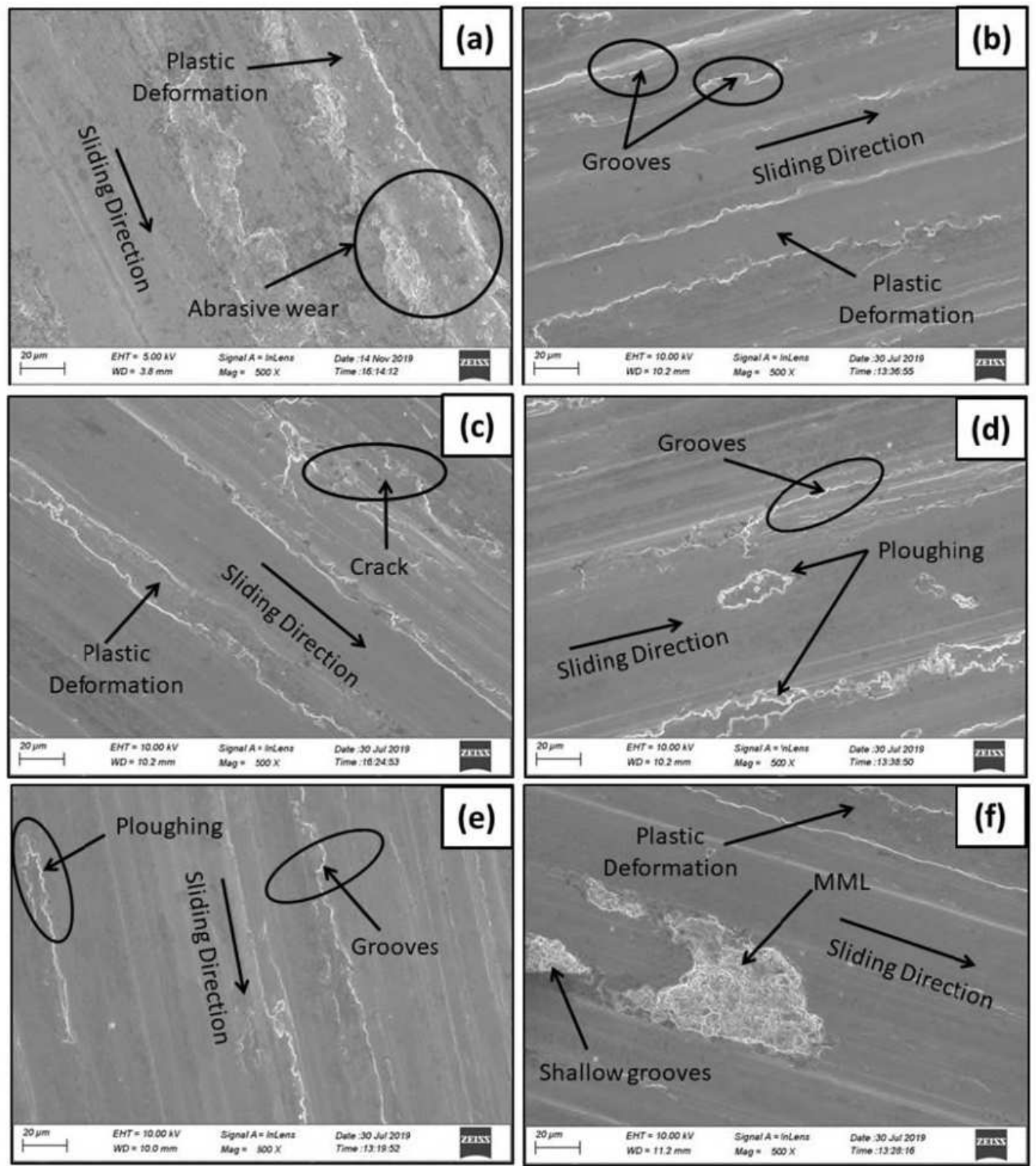

Fig. 12 Worn surface on Al7075/6wt\% SiC composite: (a) (Exp-2); (b) (Exp-6); (c) (Exp-10); (d) (Exp-14); (e) (Exp-15); (f) (Exp-16).

\section{Conclusions}

Depending upon experimental value of response characteristics the Grey-Fuzzy analysis was done to find optimize parameter on the wear rate of composite. Based on these experiments, the following observations can be concluded below:

(i) $\mathrm{TiB}_{2}$ particles reinforced $\mathrm{Al} 7075 / 6 \mathrm{wt} . \% \mathrm{SiC}$ aluminium matrix composite successfully fabricated by the stir casting process.

(ii) EDX analysis revealed the existence of $\mathrm{SiC}$ particulates in the aluminium matrix.

(iii) SEM micrograph reveals that $\mathrm{SiC}$ particulates were uniformly distributed throughout the composite with minimum agglomeration. 
(iv) The grey-fuzzy inspection noticed that the optimal parameter combinations of control factors are $10 \mathrm{~N}$ load, $2 \mathrm{~m} / \mathrm{s}$ sliding speed, and $500 \mathrm{~m}$ sliding distance.

(v) As per residual plots, individual data was observed to follow a far better distribution as every dot was nearer to the line.

(vi) Worn surface revealed that abrasive wear and grooves reduce with enhancing applied load. It is also perceived that higher sliding speed formed a mechanically mixed layer.

\section{$\underline{\text { Declarations }}$}

\section{Funding}

There are currently no Funding Sources in this work.

\section{Conflict of Interest}

The authors declare that they have no conflict of interest.

\section{Availability of data and materials}

All data sources are described in this study are directed at the corresponding author.

\section{Authors' Contribution}

Abhijit Bhowmik fabricated, tested and data analysis of aluminium matrix composite. Ajay Biswas prepared the introduction part and microstructure evaluation. All authors read and approved the final manuscript for publication.

\section{Compliance of ethical standard}

Authors declare that they have to collect documentation of compliance with ethical standards.

\section{Consent to participate}

Not Applicable

\section{Consent for Publication}

Not Applicable

\section{Acknowledgements}

Authors wish to thank CIC of Tripura University for SEM and EDX analysis.

\section{References}

1. Deuis, R. L., Subramanian, C., \& Yellup, J. M. (1997). Dry sliding wear of aluminium composites-a review. Composites science and technology, 57(4), 415-435.

2. Suresha, S., \& Sridhara, B. K. (2010). Effect of addition of graphite particulates on the wear behaviour in aluminium-silicon carbide-graphite composites. Materials \& Design, 31(4), 1804-1812. 
3. Uvaraja, V. C., Natarajan, N., Sivakumar, K., Jegadheeshwaran, S., \& Sudhakar, S. (2015). Tribological behavior of heat treated Al 7075 aluminium metal matrix composites. Indian Journal of Engineering and Materials Sciences (IJEMS), 22(1), 51-61.

4. Bandhu, D., Thakur, A., Purohit, R., Verma, R. K., \& Abhishek, K. (2018). Characterization \& evaluation of A17075 MMCs reinforced with ceramic particulates and influence of age hardening on their tensile behavior. Journal of Mechanical Science and Technology, 32(7), 3123-3128.

5. Yadav, P. K., \& Dixit, G. (2018). Erosive-Corrosive Wear of Aluminium-Silicon Matrix (AA336) and $\mathrm{SiCp} / \mathrm{TiB}_{2}$ p Ceramic Composites. Silicon, 1-12.

6. Moona, G., Walia, R. S., Rastogi, V., \& Sharma, R. (2018). Aluminium metal matrix composites: A retrospective investigation. Indian Journal of Pure \& Applied Physics (IJPAP), 56(2), 164-175.

7. Sharma, P., Paliwal, K., Dabra, V., Sharma, S., Sharma, N., \& Singh, G. (2018). Influence of Silicon Carbide/Graphite addition on properties of AA6082 reinforced composites. Australian Journal of Mechanical Engineering, 1-9.

8. Baskaran, S., Anandakrishnan, V., \& Duraiselvam, M. (2014). Investigations on dry sliding wear behavior of in situ casted AA7075-TiC metal matrix composites by using Taguchi technique. Materials \& Design, 60, 184-192.

9. Kaushik, N., \& Singhal, S. (2018). Hybrid combination of Taguchi-GRA-PCA for optimization of wear behavior in AA6063/SiCp matrix composite. Production \& Manufacturing Research, 6(1), 171-189.

10. Jayakumar, E., Praveen, A. P., Rajan, T. P. D., \& Pai, B. C. (2018). Studies on Tribological Characteristics of Centrifugally Cast SiCp-Reinforced Functionally Graded A319 Aluminium Matrix Composites. Transactions of the Indian Institute of Metals, 71(11), 2741-2748.

11. Bains, P. S., Sidhu, S. S., \& Payal, H. S. (2016). Fabrication and machining of metal matrix composites: a review. Materials and Manufacturing Processes, 31(5), 553-573.

12. Kumar, V., \& Sharma, V. (2019). Effects of $\mathrm{SiC}, \mathrm{Al}_{2} \mathrm{O}_{3}$, and $\mathrm{ZrO}_{2}$ particles on the LBMed characteristics of $\mathrm{Al} / \mathrm{SiC}, \mathrm{Al} / \mathrm{Al}_{2} \mathrm{O}_{3}$, and $\mathrm{Al} / \mathrm{ZrO}_{2} \mathrm{MMCs}$ prepared by stir casting process. Particulate Science and Technology, 37(6), 766-776.

13. Meti, V. K. V., Shirur, S., Nampoothiri, J., Ravi, K. R., \& Siddhalingeshwar, I. G. (2018). Synthesis, Characterization and Mechanical Properties of AA7075 Based MMCs Reinforced With $\mathrm{TiB}_{2}$ Particles Processed Through Ultrasound Assisted In-Situ Casting Technique. Transactions of the Indian Institute of Metals, 71(4), 841-848.

14. Reddy, P. S., Kesavan, R., \& Ramnath, B. V. (2018). Investigation of mechanical properties of aluminium 6061-silicon carbide, boron carbide metal matrix composite. Silicon, $10(2), 495-502$. 
15. Manimaran, R., Jayakumar, I., Mohammad Giyahudeen, R., \& Narayanan, L. (2018). Mechanical properties of fly ash composites-A review. Energy Sources, Part A: Recovery, Utilization, and Environmental Effects, 40(8), 887-893.

16. Kumar, B., \& Menghani, J. V. (2016). Aluminium-based metal matrix composites by stir casting: a literature review. International Journal of Materials Engineering Innovation, 7(1), $1-14$.

17. Jiang, J., \& Wang, Y. (2015). Microstructure and mechanical properties of the semisolid slurries and rheoformed component of nano-sized SiC/7075 aluminum matrix composite prepared by ultrasonic-assisted semisolid stirring. Materials Science and Engineering: A, 639, 350-358.

18. Kumar, R., \& Dhiman, S. (2013). A study of sliding wear behaviors of Al-7075 alloy and Al-7075 hybrid composite by response surface methodology analysis. Materials \& Design, 50, 351-359.

19. Faisal, N., \& Kumar, K. (2018). Mechanical and tribological behaviour of nano scaled silicon carbide reinforced aluminium composites. Journal of Experimental Nanoscience, 13(sup1), S1-S13.

20. Prasad, V. J., Rao, K. N., \& Babu, N. K. (2020). Mechanical and Tribological characterization of aluminum metal matrix composite reinforced with micro ceramic particles $\left(\mathrm{TiB}_{2} / \mathrm{SiC}\right)$. Materials Today: Proceedings, 23, 637-641.

21. Akbari, M. K., Baharvandi, H. R., \& Shirvanimoghaddam, K. (2015). Tensile and fracture behavior of nano/micro $\mathrm{TiB}_{2}$ particle reinforced casting A356 aluminum alloy composites. Materials \& Design (1980-2015), 66, 150-161.

22. Bhowmik, A., Dey, D., \& Biswas, A. (2020). Comparative Study of Microstructure, Physical and Mechanical Characterization of $\mathrm{SiC} \mathrm{TiB}_{2}$ Reinforced Aluminium Matrix Composite. Silicon, 1-8.

23. Poria, S., Sahoo, P., \& Sutradhar, G. (2016). Tribological characterization of stir-cast aluminium-TiB2 metal matrix composites. Silicon, 8(4), 591-599.

24. Meti, V. K. V., Shirur, S., Nampoothiri, J., Ravi, K. R., \& Siddhalingeshwar, I. G. (2018). Synthesis, Characterization and Mechanical Properties of AA7075 Based MMCs Reinforced with $\mathrm{TiB}_{2}$ Particles Processed Through Ultrasound Assisted In-Situ Casting Technique. Transactions of the Indian Institute of Metals, 71(4), 841-848.

25. Raju, S. S., Rao, G. S., \& Samantra, C. (2019). Wear behavioral assessment of Al-CSApMMCs using grey-fuzzy approach. Measurement, 140, 254-268.

26. Chamarthi, P., \& Nagadolla, R. (2019). Grey Fuzzy Optimization of CNC turning parameters on AA6082/Sic/Gr Hybrid MMC. Materials Today: Proceedings, 18, 3683-3692. 
27. Baskaran, S., Anandakrishnan, V., \& Duraiselvam, M, Investigations on dry sliding wear behavior of in situ casted AA7075-TiC metal matrix composites by using Taguchi technique, Materials \& Design, 60 (2014) 184-192.

28. Radhika, N., \& Raghu, R, Investigation on Mechanical Properties and Analysis of Dry Sliding Wear Behavior of Al LM13/AlN Metal Matrix Composite Based on Taguchi's Technique, Journal of Tribology, 139(4) (2017) 041602.

29. Bhaskar, S., Kumar, M., \& Patnaik, A, Silicon Carbide Ceramic Particulate Reinforced AA2024 Alloy Composite-Part I: Evaluation of Mechanical and Sliding Tribology Performance, Silicon, (2019) 1-23.

30. Kaushik, N., \& Singhal, S, Hybrid combination of Taguchi-GRA-PCA for optimization of wear behavior in AA6063/SiCp matrix composite, Production \& Manufacturing Research, 6(1) (2018) 171-189.

31. Dey, S., Deb, M., \& Das, P. K, Chemical Characterization and Tribological Behavior of Kitchen Chimney Dump Lard (KCDL) as a Bio-lubricant Chemical Characterization and Tribological Behavior of Kitchen Chimney Dump Lard (KCDL) as a Bio-lubricant, Revue des Composites et des Matériaux Avancés, 29(3) (2019) 145-150.

32. Datta, S., Bandyopadhyay, A., \& Pal, P. K, Grey-based Taguchi method for optimization of bead geometry in submerged arc bead-on-plate welding, The International Journal of Advanced Manufacturing Technology, 39(11-12) (2008) 1136-1143.

33. Roy, S., Das, A. K., \& Banerjee, R, Application of Grey-Taguchi based multi-objective optimization strategy to calibrate the PM-NHC-BSFC trade-off characteristics of a CRDI assisted CNG dual-fuel engine, Journal of natural gas science and engineering, 21 (2014) 524-531.

34. Lin, C. L., Lin, J. L., \& Ko, T. C, Optimisation of the EDM process based on the orthogonal array with fuzzy logic and grey relational analysis method, The International Journal of Advanced Manufacturing Technology, 19(4) (2002) 271-277.

35. Lin, J. L., \& Lin, C. L, The use of grey-fuzzy logic for the optimization of the manufacturing process, Journal of Materials Processing Technology, 160(1) (2005) 9-14.

36. Pandey, R. K., \& Panda, S. S, Optimization of bone drilling parameters using grey-based fuzzy algorithm, Measurement, 47 (2014) 386-392.

37. Singh, A., Datta, S., Mahapatra, S. S., Singha, T., \& Majumdar, G, Optimization of bead geometry of submerged arc weld using fuzzy based desirability function approach, Journal of Intelligent Manufacturing, 24(1) (2013) 35-44.

38. Ambigai, R., \& Prabhu, S, Fuzzy logic algorithm based optimization of the tribological behavior of Al-Gr-Si ${ }_{3} \mathrm{~N}_{4}$ hybrid composite, Measurement, 146 (2019) 736-748. 
39. Dey, S., Deb, M., \& Das, P. K, Application of fuzzy-assisted grey Taguchi approach for engine parameters optimization on performance-emission of a CI engine, Energy Sources, Part A: Recovery, Utilization, and Environmental Effects, (2019) 1-17.

40. Roy, S., Das, A. K., \& Banerjee, R, Grey-Fuzzy Taguchi approach for multi-objective optimization of performance and emission parameters of a single cylinder crdi engine coupled with EGR, International Journal of Automotive Technology, 17(1) (2016) 1-12.

41. Rajmohan, T., Palanikumar, K., \& Prakash, S, Grey-fuzzy algorithm to optimise machining parameters in drilling of hybrid metal matrix composites, Composites Part B: Engineering, 50 (2013) 297-308.

42. Bhowmik, A., Dey, D., \& Biswas, A, Tribological behaviour of Aluminium-Titanium

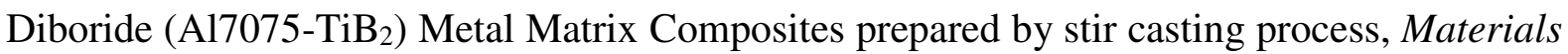
Today: Proceedings, $26(2$ (2020) 2000-2004.

43. Sardar, S., Karmakar, S. K., \& Das, D, Microstructure and Tribological Performance of Alumina-Aluminum Matrix Composites Manufactured by Enhanced Stir Casting Method, Journal of Tribology, 141(4) (2019) 041602. 
Figures
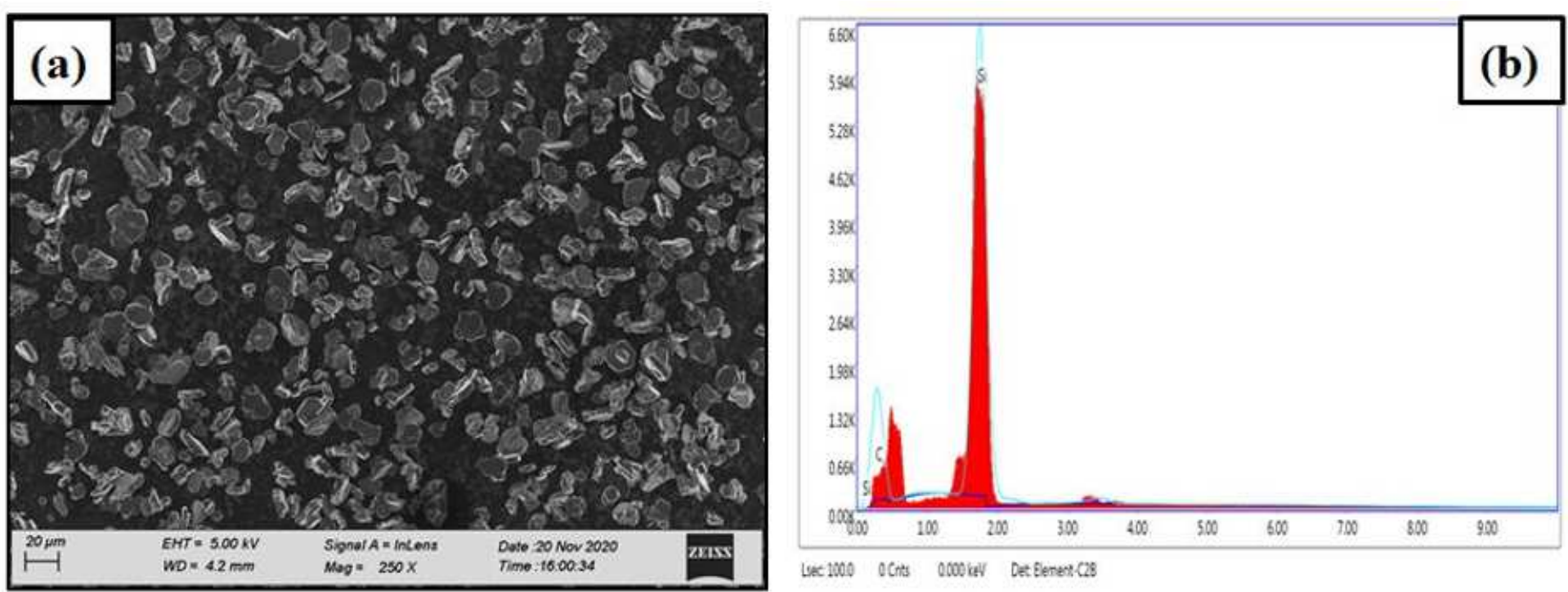

Figure 1

(a) Micrograph and (b) EDX of SiC ceramic particles

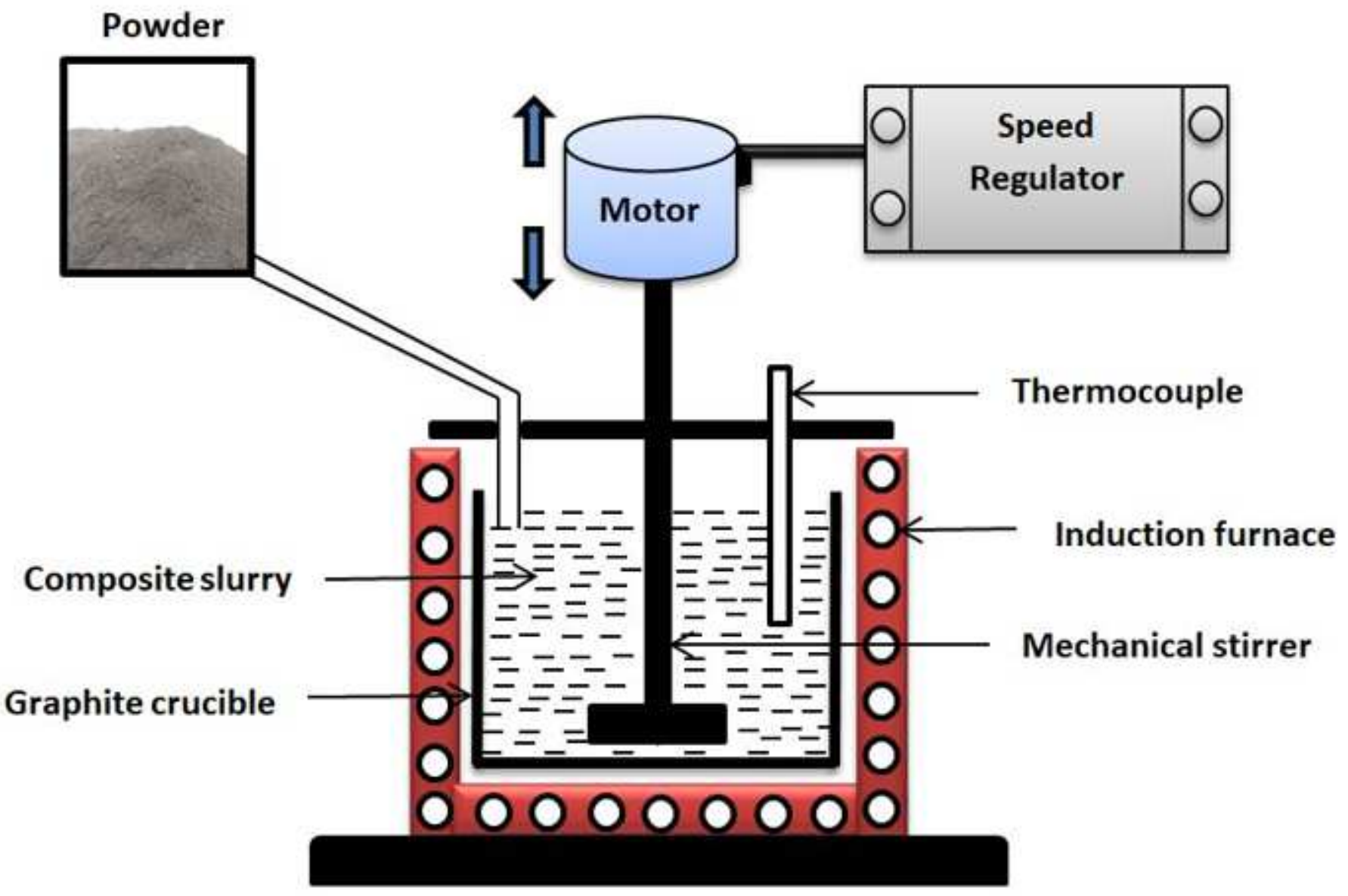

Figure 2 
Schematic representation of stir casting fabrication setup

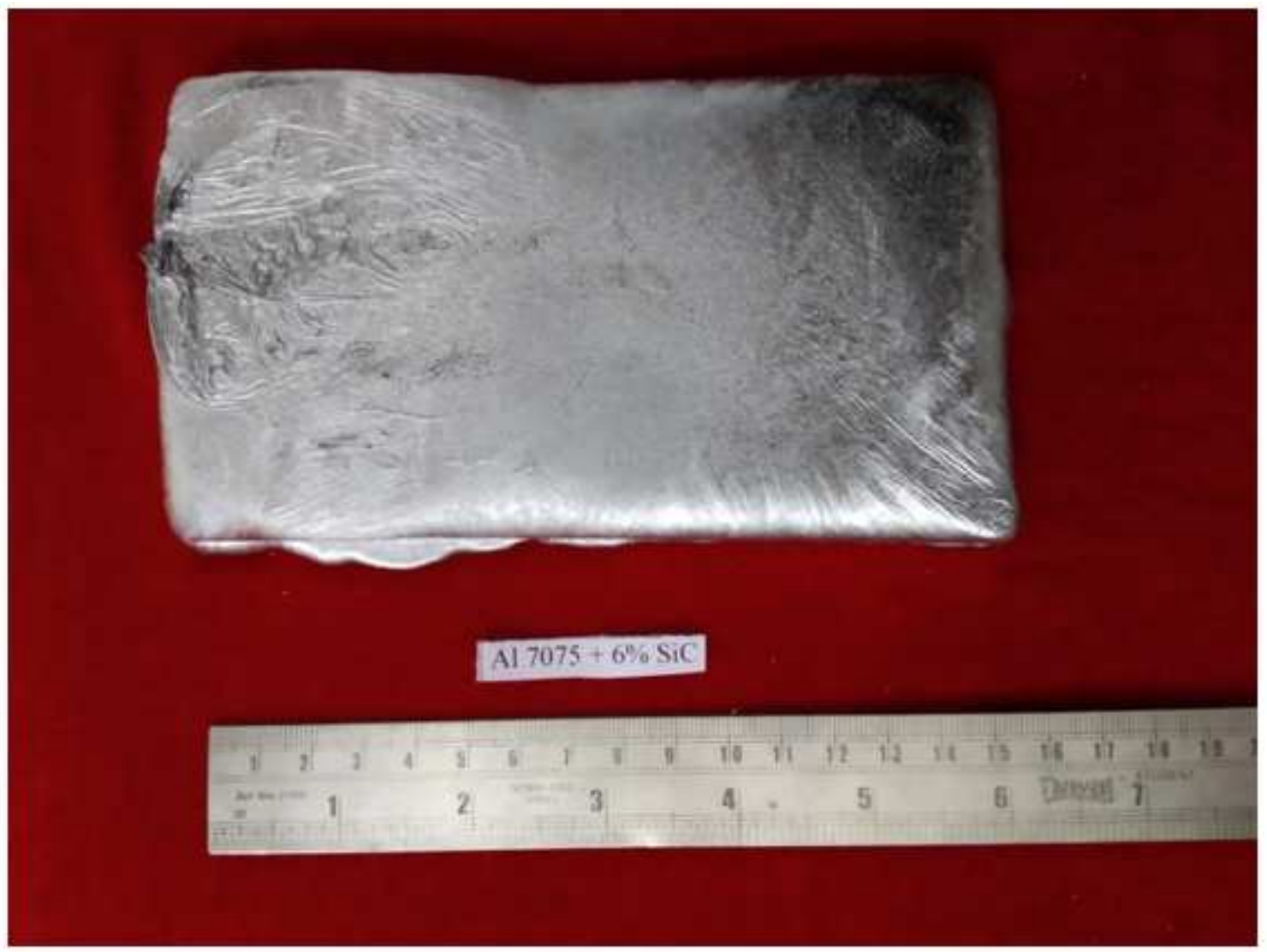

Figure 3

Casted composite fabricated by stir casting 


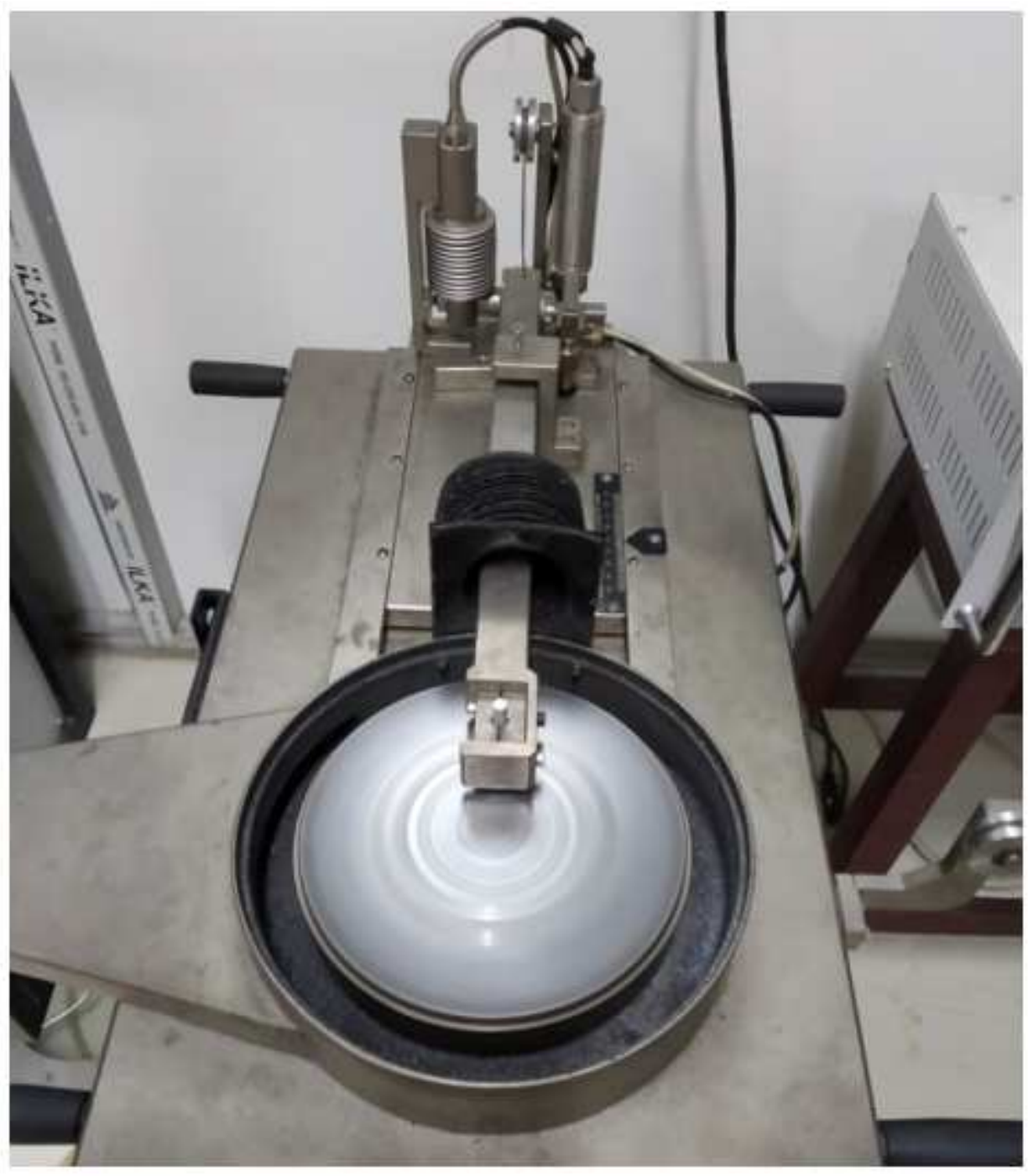

Figure 4

Pin on Disc wear setup (DUCOM's, TR 20LE-M5) 


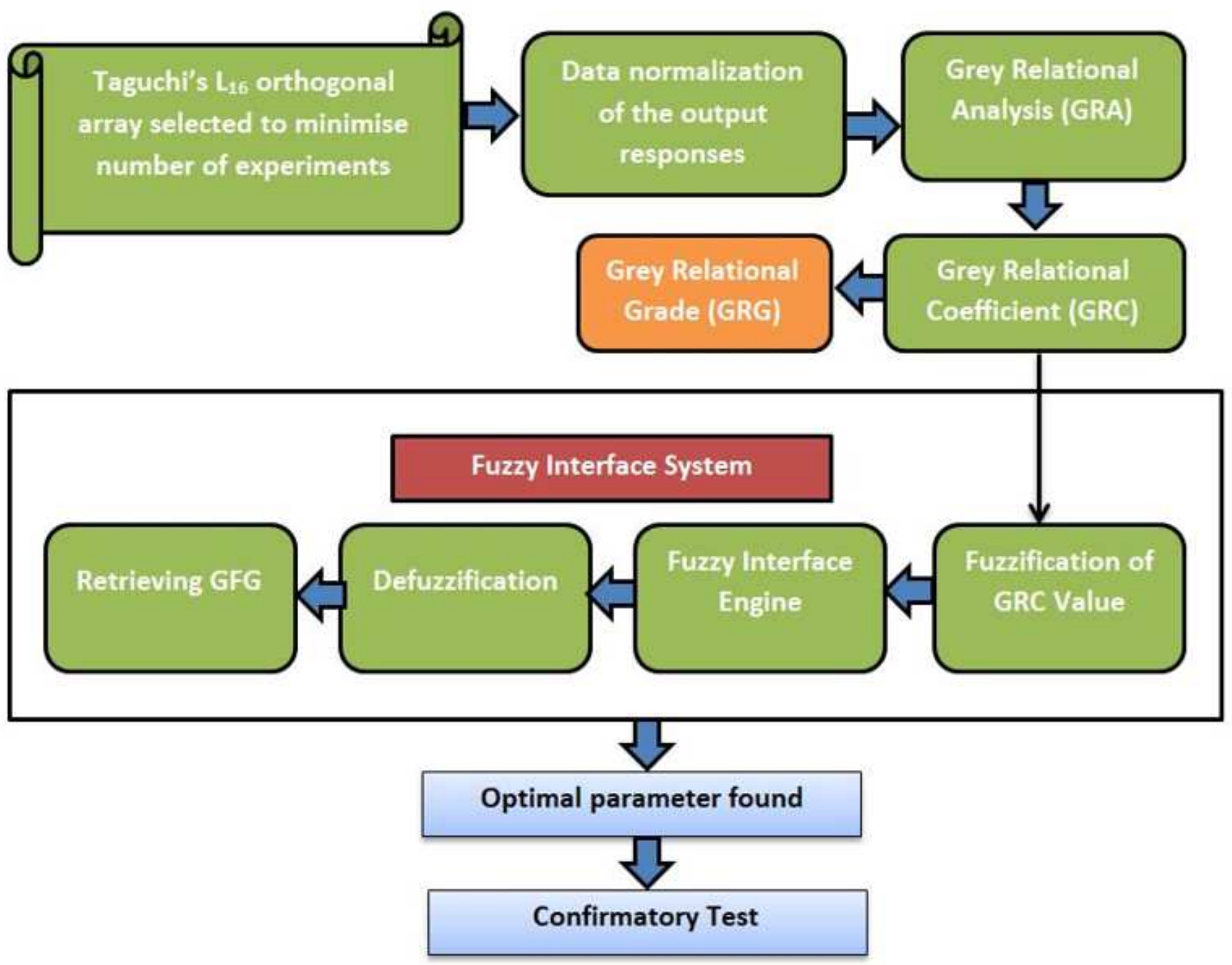

Figure 5

Steps include grey-fuzzy approach
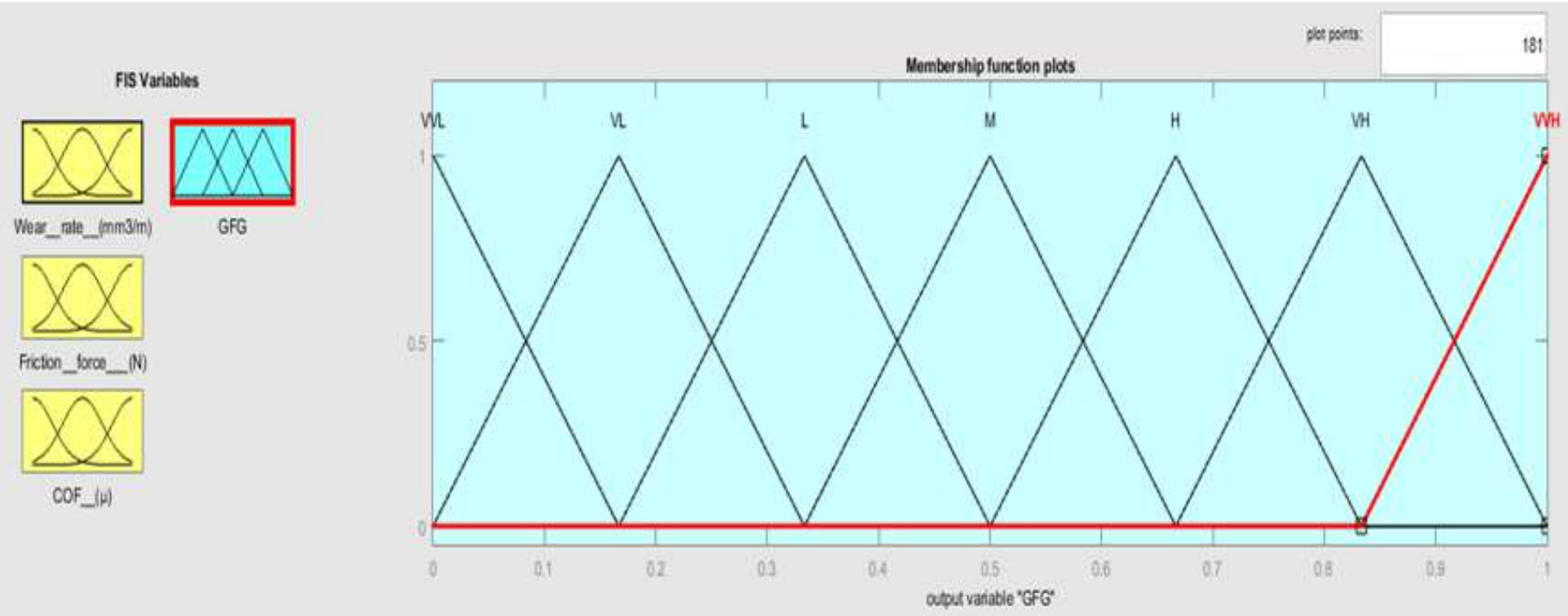
Figure 6

Structure of seven fuzzy subsets for GFG

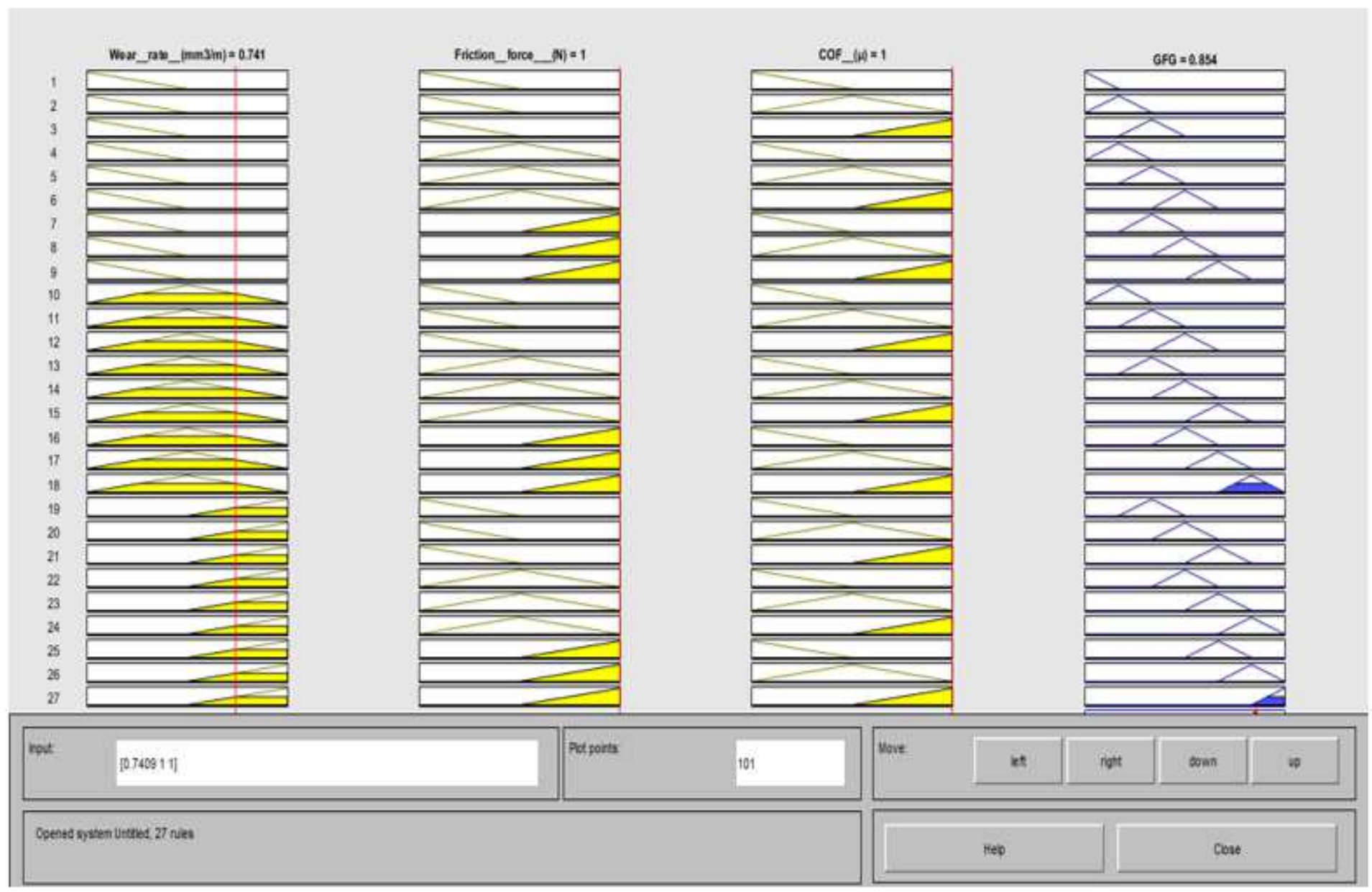

Figure 7

Fuzzy logic membership function for GFG

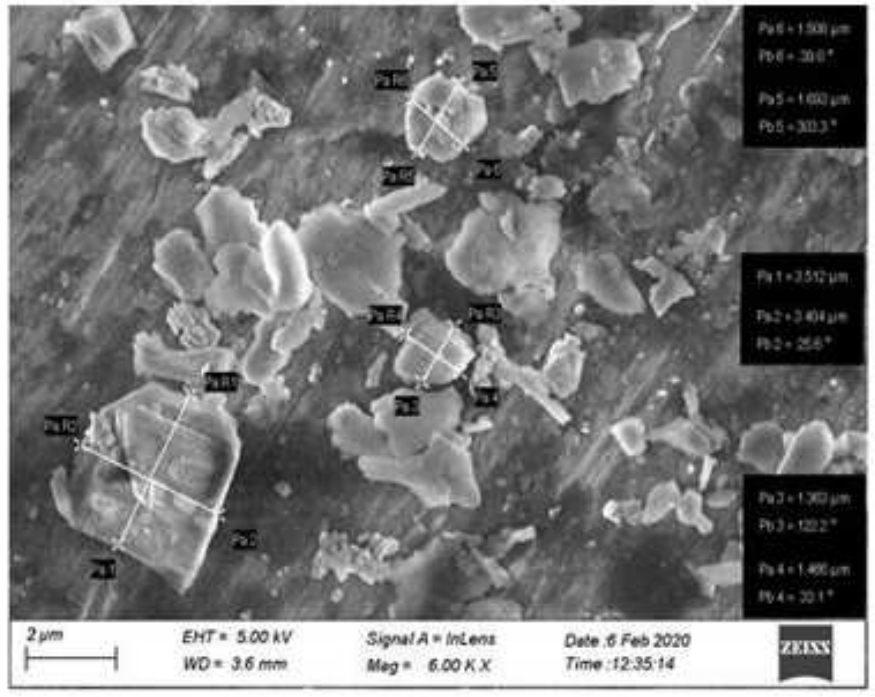

(a)

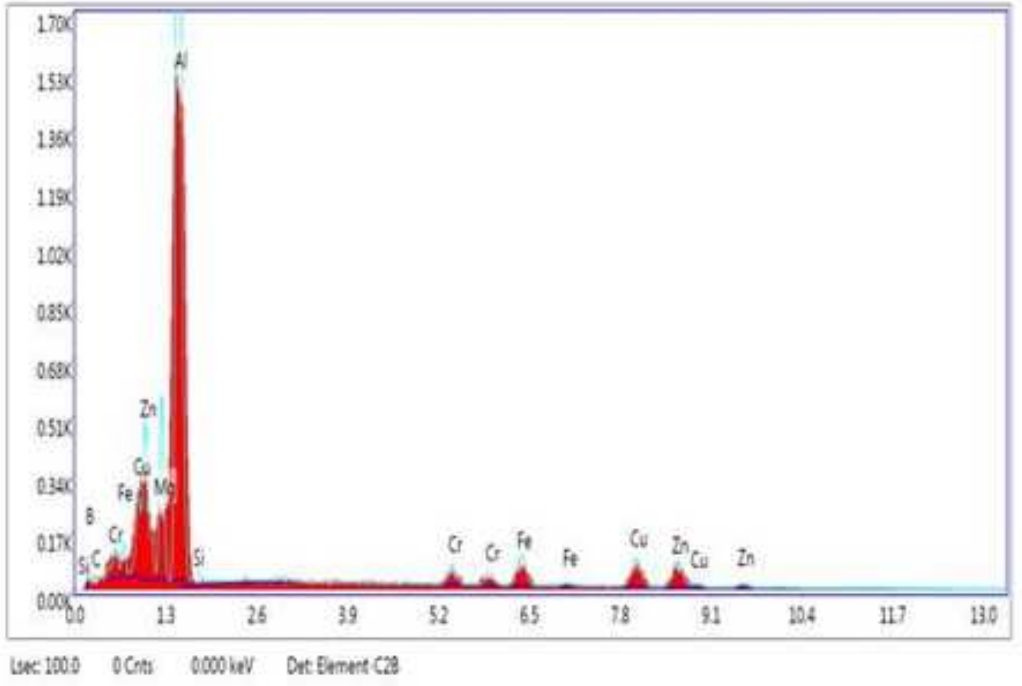

(b) 
Figure 8

(a) SEM microscopic structure and (b) EDX spectra curves of Al7075/6wt.\% SiC

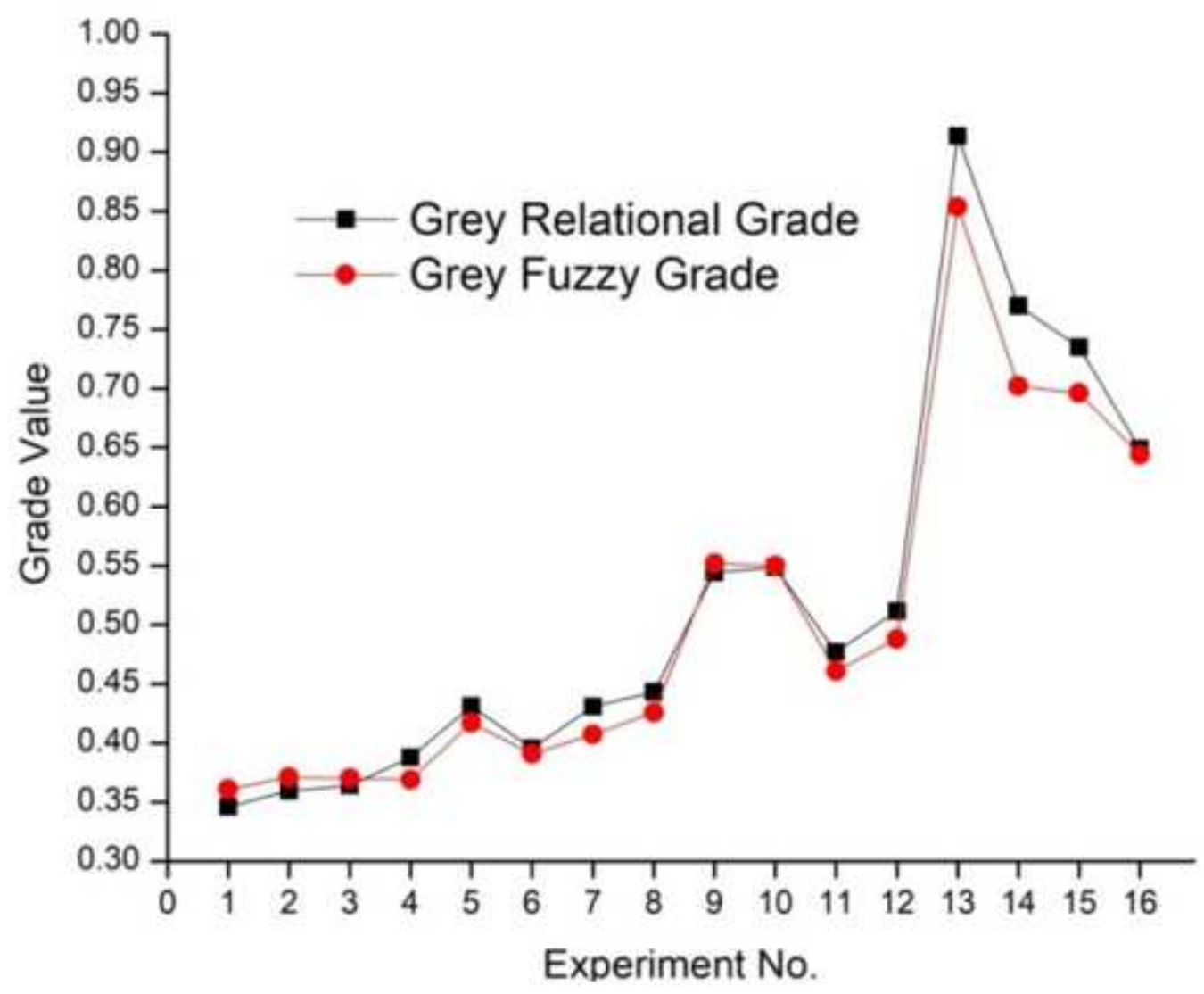

Figure 9

Compare in between GRG and GFG 


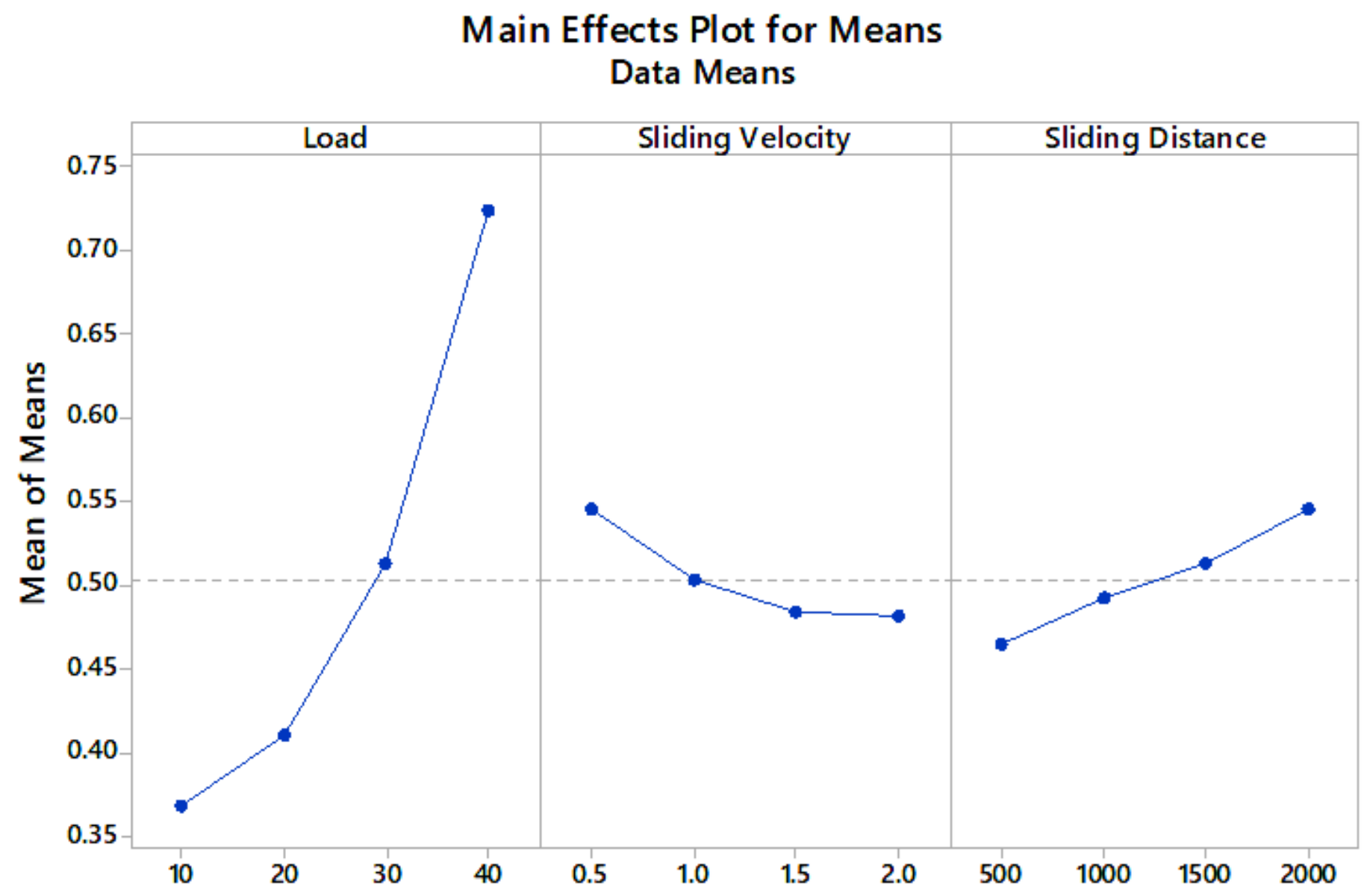

Figure 10

Response graph plot for GFG 


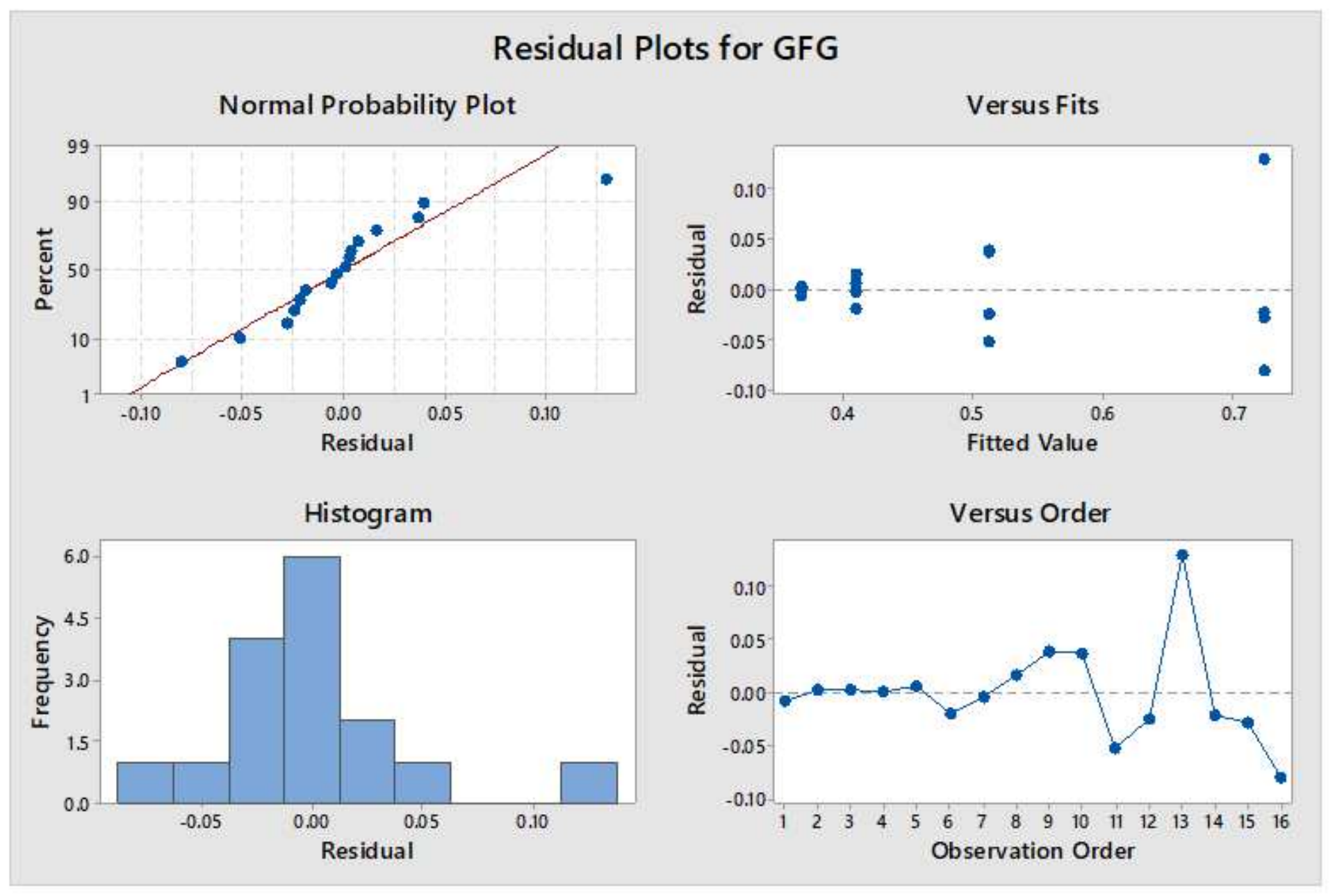

Figure 11

Residual plot of grey fuzzy grade 

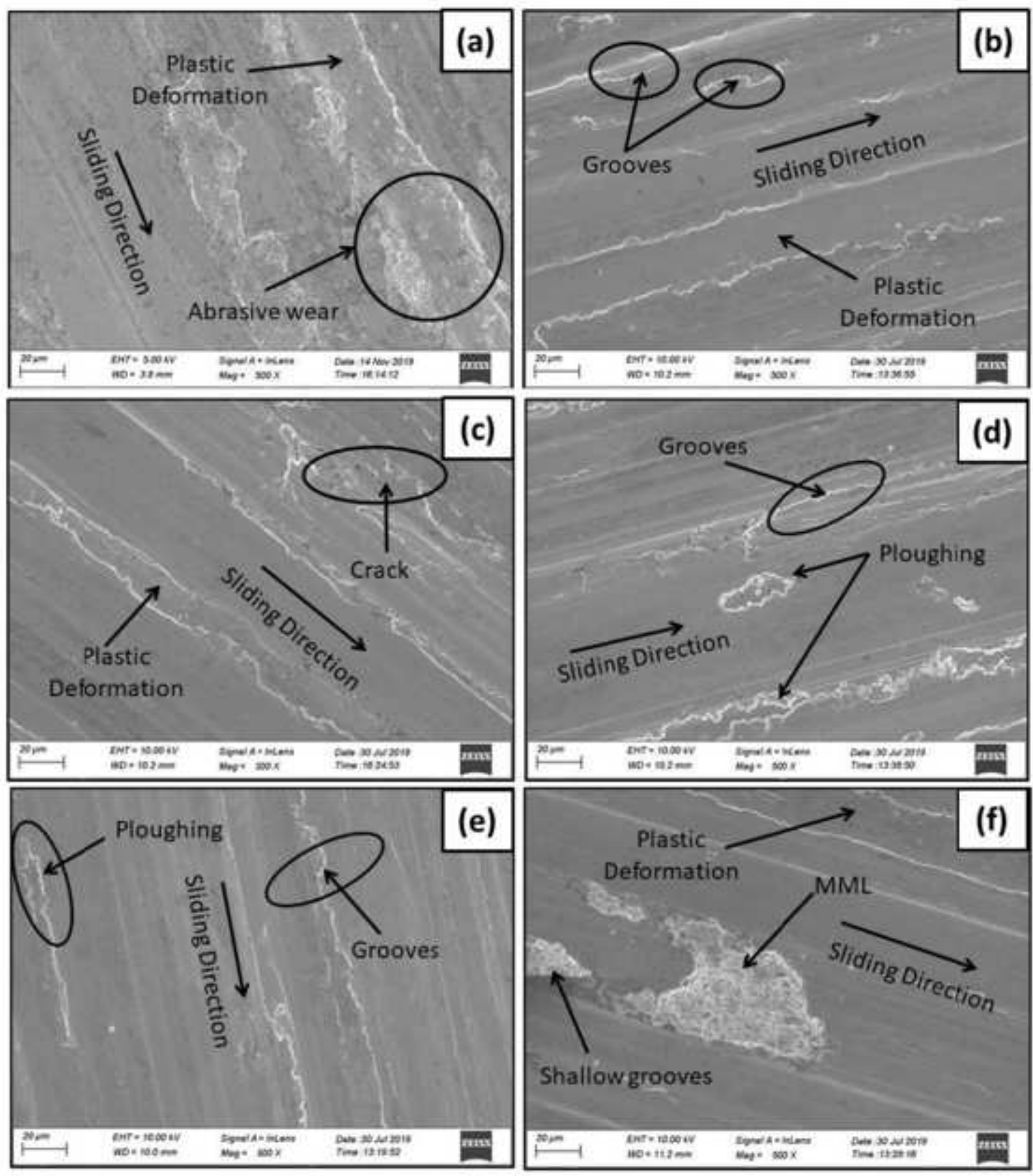

Figure 12

Worn surface on Al7075/6wt\% SiC composite: (a) (Exp-2); (b) (Exp-6); (c) (Exp-10); (d) (Exp-14); (e) (Exp15); (f) (Exp-16). 